\title{
MANF Ablation Causes Prolonged Activation of the UPR without Neurodegeneration in the Mouse Midbrain Dopamine System
}

\author{
Emmi Pakarinen, ${ }^{1}$ (1)Tatiana Danilova, ${ }^{1, *}$ Vootele Võikar, ${ }^{2, *}$ Piotr Chmielarz, ${ }^{1,3}$ (DPetteri Piepponen, ${ }^{4}$ \\ ․ Mikko Airavaara, ${ }^{1}$-Mart Saarma, ${ }^{1,+}$ and Maria Lindahl ${ }^{1, \dagger}$
}

https://doi.org/10.1523/ENEURO.0477-19.2019

${ }^{1}$ Institute of Biotechnology, HiLIFE, University of Helsinki, Helsinki FI-00014, Finland, ${ }^{2}$ Neuroscience Center/ Laboratory Animal Center, HiLIFE, University of Helsinki, Helsinki FI-00014, Finland, ${ }^{3}$ Department of Brain Biochemistry, Institute of Pharmacology, Polish Academy of Sciences, Kraków 31-343, Poland, and ${ }^{4}$ Division of Pharmacology and Pharmacotherapy, Faculty of Pharmacy, University of Helsinki, Helsinki FI-00014, Finland

\section{Visual Abstract}

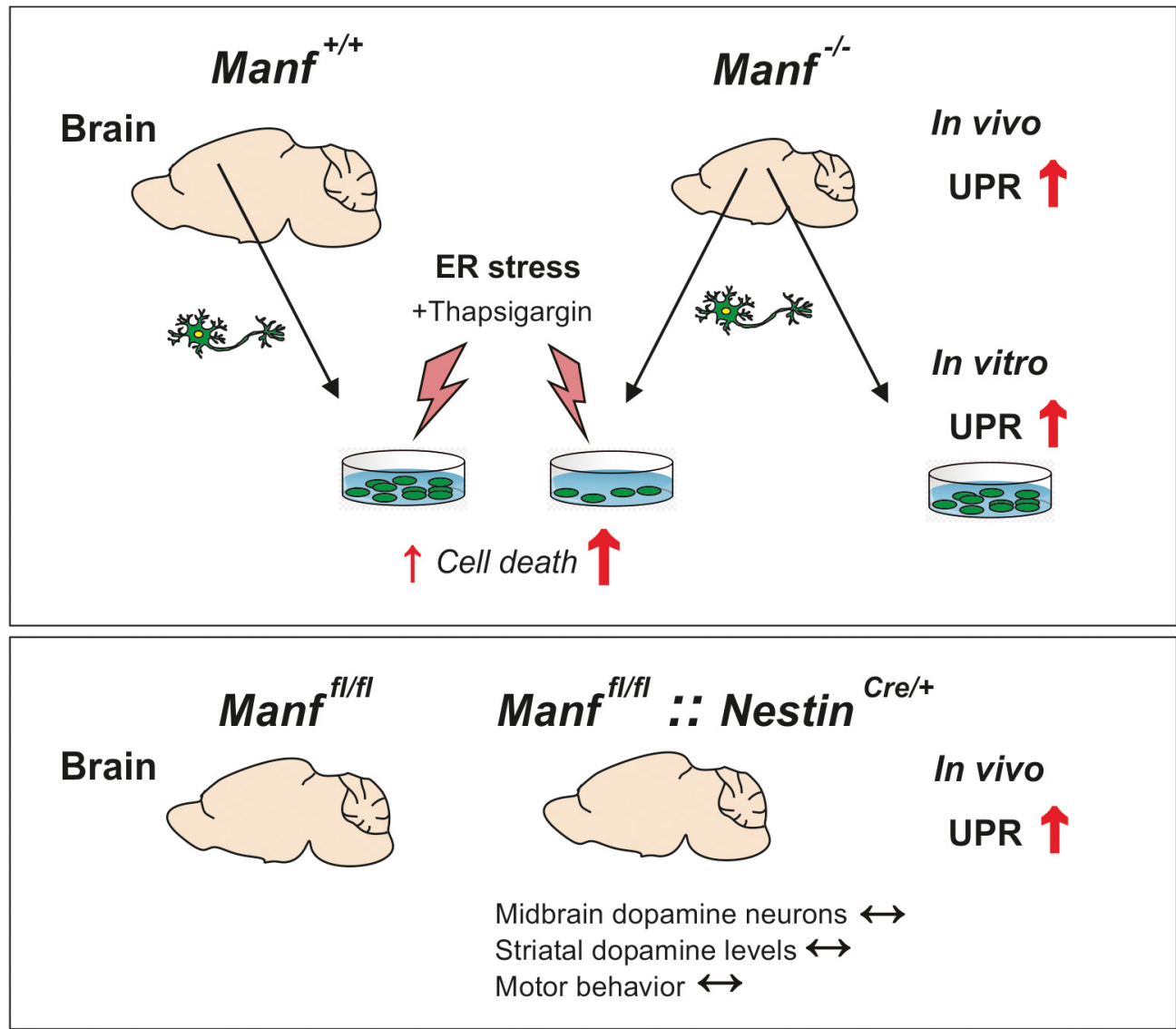

Mesencephalic astrocyte-derived neurotrophic factor (MANF) is an endoplasmic reticulum (ER) localized protein that regulates ER homeostasis and unfolded protein response (UPR). The biology of endogenous MANF in the mammalian brain is unknown and therefore we studied the brain phenotype of MANF-deficient female and male mice at different ages focusing on the midbrain dopamine system and cortical neurons. We show that a 


\section{Significance Statement}

Exogenous mesencephalic astrocyte-derived neurotrophic factor (MANF) is neuroprotective in animal models of Parkinson's disease and stroke, but the function of endogenous MANF in neurons is still elusive. This is the first study on the role of endogenous MANF in the adult mouse brain with focus on the midbrain dopamine system. We discovered chronic unfolded protein response (UPR) in the brains of mice lacking MANF. Despite activation of all three UPR pathways, we did not observe degeneration of dopamine neurons, which contrasts to the previously reported detrimental effect of chronic UPR in pancreatic $\beta$ cells lacking MANF. Our findings highlight the complexity of the UPR and reveal that the terminal consequences of chronic UPR differ in cell types and context.

lack of MANF from the brain led to the chronic activation of UPR by upregulation of the endoribonuclease activity of the inositol-requiring enzyme $1 \alpha(\operatorname{IRE} 1 \alpha)$ pathway. Furthermore, in the aged MANF-deficient mouse brain in addition the protein kinase-like ER kinase (PERK) and activating transcription factor 6 (ATF6) branches of the UPR pathways were activated. Neuronal loss in neurodegenerative diseases has been associated with chronic ER stress. In our mouse model, increased UPR activation did not lead to neuronal cell loss in the substantia nigra (SN), decrease of striatal dopamine or behavioral changes of MANF-deficient mice. However, cortical neurons lacking MANF were more vulnerable to chemical induction of additional ER stress in vitro. We conclude that embryonic neuronal deletion of MANF does not cause the loss of midbrain dopamine neurons in mice. However, endogenous MANF is needed for maintenance of neuronal ER homeostasis both in vivo and in vitro.

Key words: CNS; dopamine; ER stress; knock-out mice; MANF; unfolded protein response

\section{Introduction}

Mesencephalic astrocyte-derived neurotrophic factor (MANF) is a small, endoplasmic reticulum (ER) localized protein with survival-promoting effects and neuroprotective properties (Petrova et al., 2003; Voutilainen et al., 2009). Importantly, MANF has been associated with ER function as its expression is increased in response to several ER stress inducers and it is secreted by ER calcium depletion (Apostolou et al., 2008; Glembotski et al., 2012). ER stress is a phenomenon caused by high levels of

Received November 18, 2019; accepted December 20, 2019; First published January 31, 2020.

M.S., M.A., and M.L. are inventors in the MANF-related United States patent (9592270B2, Neurotrophic factor MANF and uses thereof) that is owned by Herantis Pharma Plc. M.S. is a shareholder in this company. All other authors declare no competing financial interests.

Author contributions: E.P., T.D., V.V., M.A., M.S., and M.L. designed research; E.P., T.D., P.P., and M.L. performed research; P.C. contributed unpublished reagents/analytic tools; E.P., T.D., V.V., P.C., P.P., M.A., M.S., and M.L. analyzed data; E.P., M.S., and M.L. wrote the paper.

This work was supported by the Jane and Aatos Erkko Foundation, Sigrid Jusélius Foundation, and Academy of Finland Grants 310891 and 117044. Mouse Behavioral Phenotype Facility is supported by Biocenter Finland and Helsinki Institute of Life Science.

*T.D., and V.V. contributed equally to this work.

†M.S. and M.L. contributed equally to this work.

Acknowledgements: We thank Sari Tynkkynen, Congjun Zheng, Mari Heikkinen, and Ronja Hotakainen for excellent technical assistance. We also thank NIH KOMP for the MANF-targeted ESC clone.

Correspondence should be addressed to Maria Lindahl at maria.lindahl@ helsinki.fi.

https://doi.org/10.1523/ENEURO.0477-19.2019

Copyright (C) 2020 Pakarinen et al.

This is an open-access article distributed under the terms of the Creative Commons Attribution 4.0 International license, which permits unrestricted use, distribution and reproduction in any medium provided that the original work is properly attributed. misfolded proteins or protein aggregates. To alleviate ER stress, cells activate the unfolded protein response (UPR) involving distinct pathways initiated by three ER transmembrane stress receptors: inositol-requiring enzyme $1 \alpha(\operatorname{RE} 1 \alpha)$, double-stranded RNA-activated protein kinase-like ER kinase (PERK), and activating transcription factor 6 (ATF6; Walter and Ron, 2011). These pathways enhance the degradation of misfolded proteins, the protein-folding capacity, and attenuate protein translation. If the UPR fails to restore homeostasis, sustained ER stress may trigger cell death. In fact, upregulation of UPR genes has been found in the postmortem brains of Parkinson's disease patients and chronic ER stress is speculated to be a contributor to neurodegenerative diseases (Hoozemans et al., 2007; Hetz and Saxena, 2017; Lindholm et al., 2017). However, we lack critical studies that show the causative role of chronic ER stress and neurodegeneration.

MANF and its paralogue, cerebral dopamine neurotrophic factor (CDNF; Lindholm et al., 2007), are structurally characterized by two domains: the amino-terminal domain is predicted to bind lipids and the carboxy-terminal domain contains an ER-retention signal and is important for the anti-apoptotic activity of MANF (Parkash et al., 2009; Hellman et al., 2011; Mätlik et al., 2015). The Manf gene promoter carries ER stress response elements I and II, which are recognized by UPR transcription factors AFT6 and spliced X-box binding protein 1 (sXBP1), thus regulating Manf mRNA expression (Oh-Hashi et al., 2013; Wang et al., 2018). Fruit flies express a single CDNF/MANF homologous gene, DmManf, which was also shown to genetically interact with Xbp1 (Lindström et al., 2016). MANF interacts with an ER chaperone glucose-regulated protein 78 (GRP78; Glembotski et al., 2012) and recent data show 
that it is the C-terminal domain of MANF that binds to the nucleotide-binding domain of GRP78, contributing to protein-folding homeostasis as a nucleotide exchange inhibitor (Yan et al., 2019).

Inactivation of the Manf gene in fruit flies causes defects in the formation of dopaminergic axonal bundles and decreased dopamine levels (Palgi et al., 2009). However, knock-down of neuronal DmManf does not affect the dopamine system in adult flies (Stratoulias and Heino, 2015). In zebrafish, knock-down of Manf results in a decreased number of dopamine neurons without phenotypic defects (Chen et al., 2012). In nematodes, a mutation in the Manf homologue was suggested to result in the gradual degeneration of dopamine neurons (Richman et al., 2018), but a recent study implicated that MANF-depleted nematodes do not after all display any dopamine phenotype (Hartman et al., 2019). We have shown that conventional MANF knock-out (KO) mice and pancreas-specific conditional $\mathrm{KO}$ mice develop insulin-dependent diabetes due to prolonged ER stress in pancreatic $\beta$ cells, leading to loss of the $\beta$ cell mass and premature death (Lindahl et al., 2014; Danilova et al., 2019a). In MANF KO mice, it was also demonstrated that MANF regulates cortical development and migration of neuronal progenitor cells (Tseng et al., 2017). Despite the suggested role of increased UPR activation behind impaired cortical development, the role of MANF in the regulation of UPR in neurons in vivo has remained unsolved. Whereas exogenous MANF has demonstrated protection of dopamine neurons in animal models of Parkinson's disease (Voutilainen et al., 2009; Liu et al., 2018), the function of endogenous MANF in the dopamine neuron maintenance in mice is not known.

To study the role of endogenous MANF in midbrain dopamine neurons and in cortical neurons, we analyzed the brains of conventional and conditional MANF KO mice with the deletion of Manf from the neural lineage of the cells in the CNS. In this study, we aimed to characterize the survival and function of the midbrain dopamine system in conditional MANF KO mice and to examine the effect of MANF absence on ER stress and its consequences for the survival of neurons.

\section{Materials and Methods}

\section{Animals}

Mice were housed in an individually ventilated cage system (Mouse IVC Green Line, Tecniplast) in a specific pathogen-free facility with a 12/12 h light/dark cycle (lights on 6 A.M. to 6 P.M.) with access to food pellets (Harlan Teklad Global Diet) and water ad libitum. Cage enrichment was provided by bedding (aspen chips $5 \times 5 \times$ $1 \mathrm{~mm}, 4 \mathrm{HP}$, Tapvei), nesting material (aspen strips, PM90L, Tapvei) and an aspen brick (100 $\times 20 \times 20 \mathrm{~mm}$, Tapvei). Development of $\mathrm{KO}$ mice used in the study have been previously described (Lindahl et al., 2014). Shortly, $\mathrm{Manf}^{-1-}$ mice were generated from an embryonic stem cell clone MANF_D06 (EPD0162_3_D06; C57BI/6N-Manf $\left.{ }^{\mathrm{tm} 1 \mathrm{a}(\mathrm{KOMP}) \mathrm{Wtsi}}\right)$. The clone included a $\beta$-galactosidase reporter cassette, which had a strong splice acceptor site between exon 2 and 3 and splicing from exon 2 to reporter cassette caused a null mutation. Manf $^{f l / f l}$ mice were produced by crossing Manf $^{+/-}$with transgenic CAG-FIp mice following removal the $\beta$-galactosidase reporter cassette. Crossing of Manf ${ }^{f / f l}$ mice with transgenic Cre mice caused removal of exon three and splicing from exon 2 to exon 4 . This resulted in a frameshift and premature stop codon and therefore with truncated Manf mRNA. Manf ${ }^{+/+}$and Manf $^{-/}$mice were maintained in an outbred ICR background and bred from heterozygous Manf $^{+/-}$parents. Manf ${ }^{f l / f l}$ mice and Manf $^{f l / f l}::$ Nestin $^{\text {Cre/+ }}$ were in a mixed ICR/C57BL/ 6JRccHsd genetic background, and $\mathrm{Nestin}^{\mathrm{Cre} /+}$ mice were only in the C57BL/6JRccHsd background (Envigo). Mice used for most of the behavioral studies were bred over eight generations in the C57BL/6JRccHsd background. Only male mice were used in the behavioral testing, whereas in the other experiments the use of either female or male mice has been informed in the figure legends. Data groups of embryonic and postnatal (P1 and P14) mice include both genders. For sample collection, brains were dissected from euthanized mice, snap frozen in liquid nitrogen and stored at $-75^{\circ} \mathrm{C}$. For immunohistochemistry, mice were heavily anaesthetized and perfused transcardially with PBS first and then with $4 \%$ paraformaldehyde (PFA) in PBS. The experiments with mice were approved by the National Animal Experiment Board in Finland, and the project license numbers were ESAVI/10564/04.10.07/2014 and ESAVI/11 865/04.10.07/2017.

\section{Blood glucose level measurements and glucose tolerance test}

Blood glucose levels were measured in random-fed animals with a glucometer (Accu-Chek Aviva Glucometer, Roche Diagnostics). For the glucose tolerance test, mice were starved for $16 \mathrm{~h}$ in their home cages. After measurement of basal blood glucose levels, D-glucose $(2 \mathrm{~g} / \mathrm{kg}$ ) was injected intraperitoneally, and blood glucose levels were measured at different time points during $2 \mathrm{~h}$.

\section{Immunohistochemistry}

PFA-fixed and paraffin-embedded brains were cut into $5-\mu \mathrm{m}$-thick sections. After paraffin removal, the sections were boiled in $10 \mathrm{mM}$ citrate buffer ( $\mathrm{pH} \mathrm{6.0)}$ for $10 \mathrm{~min}$ to retrieve antigens. The endogenous peroxidase activity was inactivated by incubation with $0.6 \%$ hydrogen peroxide in Tris-buffered saline, $\mathrm{pH} 7.4$ (TBS). Sections were washed in TBS with $0.1 \%$ Tween 20 (TBS-T) and blocked with $1.5 \%$ goat/donkey serum in TBS-T. Sections were incubated with a primary antibody overnight at $+4^{\circ} \mathrm{C}$. Primary antibodies used were anti-MANF (1:1000, 310-100, Icosagen, RRID:AB_11135308), anti-tyrosine hydroxylase (TH; 1:1000, MAB318, Millipore, RRID:AB_2201528), antiDAT (1:1000, MAB369, Millipore, RRID:AB_2190413), and anti-neuronal nuclear protein (anti-NeuN) NeuN (1:500, MAB377, Millipore, RRID:AB_2298772). After incubation with biotinylated secondary antibodies, sections were detected with Vector diaminobenzidine peroxidase substrate kit (Vector Laboratories). Secondary antibody used was horse anti-mouse (1:200, BA-2000, Vector Laboratories). 
In immunofluorescence staining, blocking solution was added for $1 \mathrm{~h}$ after antigen retrieval and the primary antibody was kept overnight. The primary antibodies used were anti-TH (1:500, MAB318, Millipore, RRID:AB_2201528) and anti-GRP78 (1:500, ab21685, Abcam, RRDI:AB_2119834). Sections were incubated with fluorescent-labeled secondary antibodies, and after a 1-h incubation, they were washed three times with TBS-T and mounted with a medium containing 4'-6-diamidino-2-phenylindole (DAPI; H-1200, Vectashield, Vector Laboratories).

\section{Counting of dopamine neurons}

To count the relative number of dopamine neurons in the substantia nigra (SN), four nigral sections within an interval of $100-120 \mu \mathrm{m}$ were selected for the staining. $\mathrm{TH}$-stained sections of the $\mathrm{SN}$ were scanned with an automated scanner (3DHistech). An area of the SN pars compacta (SNpc) from each hemisphere was defined separately based on morphologic landmarks and an estimation of dopamine neuron number was performed with a MATLAB algorithm based on intensity from TH-immunoreactive sections (Penttinen et al., 2016). In the paper of Penttinen et al. (2016), the method was validated by comparing stereological counting with this new method and analyzing dopamine neurons in different PD models. Counts were performed bilaterally and results are presented as relative change in the cell number per stained section.

\section{Optical density measurement}

Images of TH-immunostained and DAT-immunostained striatal sections were scanned with a 3DHistech scanner. Striata were defined from pictures, and optical density was measured with an Image-Pro Analyzer 7.0. The optical density of a cortical region above the striatum was subtracted as a background signal. Six sections per animal were used for the analysis. The results of integrated optical density are shown as an average and percentage of the control mice.

\section{Measurement of dopamine and serotonin levels}

The neurotransmitter levels from dissected striata were measured by high-performance liquid chromatography (HPLC) as previously described (Airavaara et al., 2006). Tissue samples were homogenized in a solution containing $0.2 \mathrm{M} \mathrm{HClO}_{4}$ and antioxidants following centrifugation at $14,000 \mathrm{rpm}$ for $35 \mathrm{~min}$. Supernatant was further filtered with Vivaspin columns by centrifugation at $9000 \mathrm{rpm}$ for $35 \mathrm{~min}$. From striatal tissues samples, concentrations of dopamine, 3,4-dihydroxyphenylacetic acid (DOPAC), homovanillic acid (HVA), serotonin, and 5hydroxyindoleacetic acid were analyzed with a HPLC including an electrochemical detector.

\section{Real-time quantitative PCR (qPCR)}

Total RNA was isolated by phenol-chloroform extraction with TRI Reagent (Molecular Research Center). Briefly, TRI reagent (Invitrogen, Thermo Fisher Scientific) was added to samples, followed by mechanical disruption by grinding with a pestle or by pulling through a needle by a syringe. Chloroform (1:4) was added to the samples, which were centrifuged at $13,000 \mathrm{rpm}$ for $15 \mathrm{~min}$. The aqueous phase was collected and isopropanol (1:1) added. For small samples, glycogen (Thermo Fisher Scientific) was added to visualize the pellet. After incubation, the samples were centrifuged at $13,000 \mathrm{rpm}$ for $15 \mathrm{~min}$, followed by washing of the pellet twice with $75 \%$ ethanol. The pellet was air-dried and dissolved in water. RNA concentration was measured by NanoDrop and equal amounts of RNA were used for synthesizing complementary DNA. RNA quality was assessed by measuring UV absorbances of the RNA samples. Reverse transcription reaction was catalyzed by RevertAid Premium Reverse Transcriptase (Thermo Fisher Scientific) or Maxima H Minus Reverse Transcriptase (Thermo Fisher Scientific) in the presence of $10 \mathrm{mM}$ NTP mix (Fermentas UAB) and oligo-d(T) (Metabion International). qPCR was performed with Lightcycler 480 SYBR Green I Master mix (Roche Diagnostics) using Lightcycler 480 Real-Time PCR System (Roche). The mRNA levels of the target gene were normalized to levels of $\beta$-actin as a reference gene, and quantification was performed by a standard curve method. Primer sequences were designed to span exon-exon junctions. Primer sequences were: Atf4 F 5'-ATG GCC GGC TAT GGA TGA T-3', Atf4 R 5'-CGA AGT CAA ACT CTT TCA GAT CCA TT-3', Atf6 $\alpha$ F 5'-GGA CGA GGT GGT GTC AGA G-3', Atf6 $\alpha$ R 5'-GAC AGC TCT TCG CTT TGG AC3', BC/10 F 5'-AAA CTG GAG CAC CTC AAA GG-3', Bc/10 R 5'-TCT CAT CGG AAT TGC ACC TA-3', Bdnf F 5'-TAC CTG GAT GCC GCA AAC AT-3', Bdnf R 5' -GCT GTG ACC CAC TCG CTA AT-3', Cdnf F 5'-GCT CAG ATG CCA AAG GAA AA-3', Cdnf R 5'-TAG GAT CTT GGT GGC TGC AT3', Chop F 5'-CCA ACA GAG GTC ACA CGC AC-3', Chop R 5'-TGA CTG GAA TCT GGA GAG CGA-3', Dat F 5'-AAC CTG TAC TGG CGG CTA TG-3', Dat R 5'-GCT GAC CAC GAC CAC ATA CA-3', Grp78 F 5'-ACC CTT ACT CGG GCC AAA TT-3', Grp78 R 5'-AGA GCG GAA CAG GTC CAT GT-3', Manf F 5'-GAC AGC CAG ATC TGT GAA CTA AAA-3', Manf R 5'-TTा CAC CCG GAG CTT CTT C-3', sXbp1 F 5'-GAG TCC GCA GCA GGT G-3', sXbp1 R 5'GTG TCA GAG TCC ATG GGA-3', Th F 5'-CCC AAG GGC TTC AGA AGA G-3', Th R 5'-GGG CAT CCT CGA TGA GAC T-3', tXbp1 F 5'-CAC CTT CTT GCC TGC TGG AC3', tXbp1 R 5'-GGG AGC CCT CAT ATC CAC AGT-3', Txnip F 5'-TCA AGG GCC CCT GGG AAC ATC-3', Txnip R 5'-GAC ACT GGT GCC ATT AAG TCA G-3'.

\section{Western blotting}

Samples were homogenized in lysis buffer composed of $10 \mathrm{mM}$ Tris- $\mathrm{HCl}$ (pH 8.0), $300 \mathrm{mM} \mathrm{NaCl}, 4 \mathrm{mM}$ EDTA, $0.2 \%$ Triton $\mathrm{X}-100$, and a protease inhibitor cocktail (cOmplete, Roche, 04693159001). Also, a phosphatase inhibitor (PhosStop, Roche, 04906837001) or $1 \mathrm{mM}$ sodium orthovanadate was added to inhibit phosphatase activity. Homogenates were incubated on ice for $1 \mathrm{~h}$, followed by centrifugation at $13,000 \mathrm{rpm}$ for $20 \mathrm{~min}$. The supernatant was collected, and protein concentrations were measured with DC protein assay (Bio-Rad Laboratories) according to the manufacturer's instructions. To equalize protein concentrations, samples were diluted in 
lysis buffer and then mixed with Laemmli buffer containing $2 \%$ 2-mercaptoethanol. Samples were heated at $+95^{\circ} \mathrm{C}$ for $5 \mathrm{~min}$. For DAT detection, striatal samples were homogenized in a $10 \mathrm{mM}$ HEPES ( $\mathrm{pH}$ 7.2), buffer containing $0.3 \mathrm{M}$ sucrose, $1 \mathrm{mM}$ EDTA and protease inhibitors. The samples were incubated with Laemmli buffer at $+37^{\circ} \mathrm{C}$ for $50 \mathrm{~min}$ and run on self-made or pre-cast gels (Bio-Rad). Proteins were transferred onto nitrocellulose membranes, which were blocked with $5 \%$ milk or $5 \%$ BSA in TBS-T for $1 \mathrm{~h}$ and incubated with primary antibody solution overnight. The primary antibodies used were: anti-GRP78 (1:1000, sc-1051, Santa Cruz Biotechnology, RRDI:AB_2119994), antielF2 $\alpha$ (1:1000, 9722, Cell Signaling, RRID:AB 2230924), antipelF2 $\alpha$ (1:1000, 9721, Cell Signaling, RRID:AB_330951), anti-GAPDH (1:3000, MAB374, Millipore, RRID:AB_2107445), anti-TH (1:1000, MAB318, Millipore, RRID:AB_2201528), antiDAT (1:1000, MAB369, Millipore, RRID:AB_2190413), antip-NF- $\kappa$ B (1:1000, 3033, Cell Signaling, RRID:AB_10859369), and anti-NF- $\kappa$ B (1:1000, 8242, Cell Signaling, RRID:AB 331284). Secondary antibody was applied for $1 \mathrm{~h}$ and detected with chemiluminescence ECL Blotting Substrate (Pierce, Thermo Fisher Scientific). The secondary antibodies used were: goat anti-mouse (1:3000, P0447, Dako), donkey anti-rabbit (1:3000, NA9340V, GE Healthcare), goat anti-rat (1:1000), and rabbit anti-goat (1:1500, P0449, Dako). Protein bands were quantified with ImageJ software. Protein amounts were normalized to GAPDH.

\section{Primary dopamine cell cultures}

To culture midbrain dopamine neurons from single embryos, the method of micro-island cultures was used. Micro-islets were drilled into four-well plates and coated with poly-ornithine. Midbrain floors were dissected from E13.5 embryos, collected in Dulbecco's media and washed with HBSS. Cells were detached by trypsin treatment at $+37^{\circ} \mathrm{C}$ for $20-30 \mathrm{~min}$. To stop the reaction, fetal bovine serum (FBS) was added and cells were triturated. After the sedimentation of cells, the supernatant was collected and the trituration repeated. Cells were centrifuged for $5 \mathrm{~min}$ at $1000 \mathrm{rpm}$. The pellet was washed twice with the media and dissolved in the media. Approximately 2000-3000 cells were added to each micro-island. Some plates were fixed on the first day in vitro (DIV1). For other plates, half of the media was changed at DIV2 and fixed at DIV5. Cells were fixed with 4\% PFA, washed and permeabilized with $0.2 \%$ Triton X-100 in PBS. Samples were blocked with 5\% horse serum $+0.2 \%$ Triton X-100 in PBS and incubated with antiTH antibody (1:1000, MAB318) overnight. Specimens were incubated with secondary antibody (1:400, Alexa Fluor 488 Goat Anti-mouse, Life Technologies, A11029) for $1 \mathrm{~h}$, and nuclei were stained with DAPI (1:5000) for $10 \mathrm{~min}$. Images from micro-islands were taken with a Leica fluorescent camera DC300F and $\mathrm{TH}+$ cells were quantified from images with ImageJ (Rueden et al., 2017). Each data point was an average of at least two micro-islands.

\section{Primary cortical cell cultures}

Cortex was collected from mouse fetuses at gestational day 16 (E16) or E17 separately and later genotyped.
Cortical pieces were washed twice with HBSS. Samples were incubated with $0.5 \%$ trypsin for $15 \mathrm{~min}$ at $+37^{\circ} \mathrm{C}$, followed by addition of HBSS $+10 \%$ FBS and DNase I. Centrifuged pellets were washed twice with HBSS+FBS solution. Neurobasal medium (Invitrogen) supplemented with B27 (1×, Invitrogen), $500 \mu \mathrm{M}$ glutamine, and primocin was added on top of the pellet and pipetted until tissue pieces were separated. Cells were centrifuged and washed with media. Dissociated neurons were counted, and cells were plated on poly-ornithine coated 96-well or 12 -well plates at the amount per well of $2.5 \times 10^{4}$ and $4 \times 10^{5}$, respectively. Half of the medium was changed every 2-4 d. Cortical neurons cultured on 12-well plates were treated with $20 \mu \mathrm{M}$ 5-fluoro-2' -deoxyuridine (F0503, Sigma-Aldrich) and $20 \mu \mathrm{M}$ uridine (U3750, Sigma-Aldrich) from DIV2 to DIV5 to reduce the number of glial cells. Treatments were performed during media change at DIV9. Neurons cultured on 96-well plates were fixed with $4 \%$ PFA. They were permeabilized with $0.2 \%$ Triton $X-100$ in PBS for $15 \mathrm{~min}$ and blocked with $5 \%$ horse serum in $0.2 \%$ Triton X-100 in PBS. A primary antibody (anti-NeuN, 1:500, MAB377, Millipore) was added to the blocking medium and incubated overnight. After incubation with a secondary antibody (1:400, Alexa Fluor 488 goat anti-mouse, Life Technologies, A11029) for $1 \mathrm{~h}$, the nuclei were stained with DAPI. Cultures were imaged with a Celllnsight CX5 instrument (Thermo Fisher Scientific) and the number of NeuN-positive cells was analyzed automatically by designed image analysis workflow in CellProfiler and CellProfiler Analyst programs (Carpenter et al., 2006; Jones et al., 2009). Neurons grown on 12-well plates were used for RNA extraction or Western blotting in the same way as described above.

\section{Multiple static rods}

The performance of a mouse on five rods with increasing diameter (rod 1: $27 \mathrm{~mm}$, rod 2: $21 \mathrm{~mm}$, rod 3: $15 \mathrm{~mm}$, rod 4: $11 \mathrm{~mm}$, rod 5: $8 \mathrm{~mm}$ ) was measured. At the beginning of a test, a mouse was placed at the end of the round beam facing away from the supporting platform. The latencies to turn $180^{\circ}$, walk $60 \mathrm{~cm}$, and possible fall off were measured within a maximum of $2 \mathrm{~min}$.

\section{Wire hanger test}

A mouse was placed in the middle of the horizontal hanger grid. The mouse was observed for $1 \mathrm{~min}$, and the latency to fall was measured.

\section{Accelerating rotarod}

Mice were trained once on an accelerating rotarod (from 4 to $40 \mathrm{rpm}$ during $4 \mathrm{~min}$ ). Later on, the same day, the latency to fall was measured with the 4-min cutoff time.

\section{Open-field activity}

Mice were placed in the corner of an open-field arena $(30 \times 30 \mathrm{~cm}$, Med Associates). The horizontal activity was monitored for $30 \mathrm{~min}$. For testing amphetamine-induced locomotor activity, mice were first habituated in the open- 
field arenas for $30 \mathrm{~min}$. Mice were then injected with $3 \mathrm{mg} /$ $\mathrm{kg} \mathrm{D}$-amphetamine intraperitoneally and placed back in the same chambers. The horizontal activity was measured for another $90 \mathrm{~min}$.

\section{Barnes maze}

A circular elevated platform (diameter $100 \mathrm{~cm}$ ) contained 20 equally distributed holes (diameter, $5 \mathrm{~cm}$ ) around the perimeter. An escape box was placed under one of the holes. Mice were trained to find the escape box during training sessions of a maximum of 3 min per time. The trial was ended either when the animal entered the box or 3 min had elapsed; in the latter case the animal was guided to the box by hand and allowed to enter it. Training was conducted three times per day (with an inter-trial interval of at least $1 \mathrm{~h}$ ) on three consecutive days. On day 4 , for testing of memory in probe trial 1 , the box was removed and mice had $1.5 \mathrm{~min}$ to navigate to the right place. For reverse training, the escape box was set at the opposite side of the maze. Reverse trainings of 3 min occurred three times per day on two consecutive days. The maze was cleaned with water between every animal. The trials were recorded with video tracking software Ethovision XT10 (Noldus). The distance traveled and the latency to find the escape box were measured during the training trial; in addition, the time spent in a zone surrounding the target hole was measured in the probe trial.

\section{Statistical analysis}

Statistical analysis was performed using either SPSS Statistics (version 24, IBM) or GraphPad Prism (version 7.04, GraphPad Software). Student's $t$ test was used when comparing two groups when data were normally distributed. If data were not normally distributed or Levene's test for equality of variances showed unequal variances, the Mann-Whitney $U$ test was used to compare two groups. If only part of the large dataset was not normally distributed, the nonparametric Mann-Whitney $U$ test was still used to make consistent analysis. Data with three groups and one factor were analyzed with one-way ANOVA, followed by Tukey's post hoc test, and if data were not normally distributed, the nonparametric Kruskal-Wallis test followed by Mann-Whitney $U$ test was used. For tests with many measurements from the same subject, we used two-way ANOVA for repeated measures. For the data, where thapsigargin was used as a treatment, two-way ANOVA was used to analyze genotype-treatment interaction, and it was followed by Tukey's post hoc test. The behavioral tests and analysis were performed blinded. All results are presented as mean \pm SEM and regarded as significant when $p<0.05$. The statistical test used are listed in Table 1 and Extended Data Table 1-1, but significant exact $p$ values from Mann-Whitney $U$ test and Tukey's post hoc test are presented in the figures due to clarity.

\section{Results}

\section{Conditional deletion of MANF in the nervous system}

Conditional MANF KO mice were produced by deleting an exon three of the Manf gene by crossing the floxed mice $\left(\right.$ Manf $\left.f^{f / f f}\right)$ with transgenic Nestin ${ }^{\mathrm{Cre} /+}$ mice. Cre recombinase expressed under the Nestin promoter in Nestin ${ }^{\mathrm{Cre} /+}$ transgenic mice is induced predominantly in the CNS (Tronche et al., 1999). Later, it was reported that in the Nestin ${ }^{\mathrm{Cre} /+}$ line used, recombination is observed in neural stem cells and neural progenitor cells from E12.5 but with incomplete efficiency (Dubois et al., 2006). Since MANF is mainly expressed in neurons in the adult mouse brain (Lindholm et al., 2008; Tseng et al., 2017; Danilova et al., 2019a,b), this recombination is expected to remove most of the MANF in the brain. Consequently, qPCR analysis showed barely detectable levels of Manf mRNA analyzed from the brain lysates from different brain areas of Manf $^{f / f /}::$ Nestin ${ }^{C r e /+}$ mice compared with littermate Manf $f^{f / f f l}$ mice (Fig. 1A; Table 1). Brain regions analyzed were selected based on their normally high MANF expression (Lindholm et al., 2008). Importantly, Manf mRNA levels were similar in the cortex between control Manf $f^{f l f l}$ and Nestin ${ }^{C r e /+}$ mice, and reduced as expected in Manffl/fl:: Nestin ${ }^{\mathrm{Cre} /+}$ mice (Fig. 1B; Table 1). This result indicates the comparable levels of Manf mRNA in Manf fl/fl and Nestin ${ }^{\mathrm{Cre} /+}$ mice. Consistent with the Manf mRNA levels, immunoreactivity for MANF with a validated MANF-specific antibody was detected in the brains of Manf $f^{f / f l}$ mice, but the signal was almost fully lost in Manf fl/fl::Nestin ${ }^{\text {Cre/ }}$, mouse brain counterstained with hematoxylin (Fig. 1C). The loss of MANF did not affect Cdnf mRNA expression levels in the Manf fl/fl::Nestin ${ }^{\text {Cre/+ }}$ brain areas (Fig. 1D; Table 1) or the Bdnf mRNA levels measured from the cortical and hippocampal tissue (Fig. 1E; Table 1).

In contrast to global Manf ${ }^{/-}$mice in the ICR strain that die prematurely (Lindahl et al., 2014) and Manf ${ }^{-1}$ mice in the C57BL/6 strain that are perinatal lethal (Neves et al., 2016; Bell et al., 2019), Manff ${ }^{f / f l}:: N e s t i n^{\text {Cre/+ }}$ mice were viable and visibly similar to littermates when followed until the age of 18 months. The body weights of Manffl/fl::Nestin Cre/+ mice were reduced at four and 16 months of age compared with the Manf f//fl controls but when comparing Manf $f^{f / f l}:$ : Nestin ${ }^{\mathrm{Cre} /+}$ mice with Nestin ${ }^{\mathrm{Cre} /+}$ mice, there was no difference in body weight (Fig. 1F; Table 1). Since conventional MANF KO mice develop diabetes by the age of seven weeks (Lindahl et al., 2014), we followed the blood glucose levels to rule out the possible development of hyperglycemia. In line with the previously published data (Lindahl et al., 2014), blood glucose levels of random-fed Manf ${ }^{f / f f l}::$ Nestin ${ }^{\text {Cre/ }+}$ mice stayed similar to Manf f/ffl controls until the age of 16 months (Fig. 1G; Table 1). The glucose tolerance test measuring insulin secretion and sensitivity was performed by injecting glucose followed by measuring the rate of glucose clearance from the blood stream. Both Manf ${ }^{f / f l}$ and Manf ${ }^{f / f /}::$ Nestin ${ }^{\mathrm{Cre} /+}$ mice showed similar glucose clearance over time (Fig. 1H; Table 1).

\section{MANF deficiency causes robust activation of IRE1 $\alpha$ signaling pathway in the brain}

Previously it has been shown that loss of MANF in pancreatic $\beta$ cells leads to chronic UPR activation in vivo (Lindahl et al., 2014). Recently, it was also demonstrated that ablation of MANF in cartilage results in upregulation of ER chaperones in vivo (Bell et al., 2019). Therefore, we 
Table 1. Statistical analysis

\begin{tabular}{|c|c|c|c|}
\hline Dataset & Data structure & Type of test & Power \\
\hline Figure $1 A$ & Non-normal distribution & Mann-Whitney $U$ & Significant $p$ values in the figure \\
\hline Figure $1 B$ & Non-normal distribution & Kruskal-Wallis, Mann-Whitney $U$ & $H_{(2)}=11.33, p=0.003$ \\
\hline Figure $1 D, E$ & Non-normal distribution & Mann-Whitney $U$ & No significance \\
\hline Figure $1 F$ & Normal distribution & One-way ANOVA, Tukey's HSD & $\begin{array}{l}\text { 4-month-old mice } F_{(2,22)}=20.42, p<0.001 ; 12 \text {-month-old mice } F_{(2,22)}= \\
\quad 6.35, p=0.007\end{array}$ \\
\hline Figure $1 G$ & Normal distribution & Two-tailed $t$ test and one-way ANOVA & $\begin{array}{l}\text { 2-month-old mice } t_{(30)}=0.93, p=0.360 ; 16 \text {-month-old mice } F_{(2,22)}=0.43 \text {, } \\
\qquad p=0.659\end{array}$ \\
\hline Figure $1 H$ & Normal distribution & Two-way RM ANOVA & Genotype $\times$ time interaction $F_{(6,54)}=0.88, p=0.517$ \\
\hline Figure $2 A-G$ & Non-normal distribution & Mann-Whitney $U$ & Significant $p$ values presented in the figure \\
\hline Figure $2 \mathrm{H}$ & Normal distribution & Two-tailed $t$ test & $\begin{array}{l}\text { Cortex Txnip } t_{(6)}=1.046, p=0.34 ; \text { Cortex Bc/10 } t_{(12)}=0.59, p=0.564 ; \mathrm{SN} \\
\quad \text { Txnip } t_{(10)}=1.15, p=0.279 ; \mathrm{SN} \mathrm{Bc/10} t_{(10)}=0.41, p=0.688\end{array}$ \\
\hline Figure $3 A$ & Normal distribution & One-way ANOVA, Tukey's HSD & $\begin{array}{c}\text { Atf6 } \alpha F_{(2,13)}=0.08, p=0.924 ; \text { Atf4 } F_{(2,13)}=0.08, p=0.927 ; \operatorname{Chop}_{(2,13)}= \\
1.19, p=0.334 ; \operatorname{Grp78} F_{(2,13)}=9.70, p=0.003 ; \operatorname{sXbp1} F_{(2,13)}=99.98 \\
\quad p<0.001 ; \operatorname{tXbp1} F_{(2,13)}=0.032, p=0.968\end{array}$ \\
\hline Figure $3 B$ & Normal distribution & One-way ANOVA, Tukey's HSD & $\begin{array}{l}\text { Atf6 } \alpha F_{(2,11)}=5.88, p=0.018 ; \text { Atf4 } F_{(2,11)}=7.13, p=0.010 ; \text { Chop } F_{(2,11)}= \\
\quad 0.25, p=0.781 ; \operatorname{Grp78} F_{(2,11)}=15.18, p=0.001 ; \operatorname{sXbp1} F_{(2,10)}=134.32, \\
\quad p<0.001 ; \operatorname{tXbp1} F_{(2,11)}=5.39, p=0.023\end{array}$ \\
\hline Figure $3 C$ & Normal distribution & One-way ANOVA & Txnip $F_{(2,11)}=1.22, p=0.331 ; B c / 10 F_{(2,11)}=1.13, p=0.358$ \\
\hline Figure $4 A$ & Normal distribution & Two-tailed $t$ test & $t_{(8)}=1.89, p=0.095$ \\
\hline Figure $4 C$ & Normal distribution & Two-tailed $t$ test & TH-fibers $t_{(8)}=0.32, p=0.760$; DAT-fibers $t_{(8)}=0.71, p=0.499$ \\
\hline Figure $4 E$ & Non-normal distribution & Kruskal-Wallis, Mann-Whitney $U$ & $\begin{array}{c}\text { DA } H_{(2)}=6.68, p=0.035, \text { DOPAC } H_{(2)}=6.68, p=0.541 ; \text { HVA } H_{(2)}=0.422, \\
p=0.810 ; 5-\mathrm{HT} H_{(2)}=1.618, p=0.445 ; 5-\mathrm{HIAA} H_{(2)}=0.23, p=0.893\end{array}$ \\
\hline Figure $5 A$ & Non-normal distribution & Kruskal-Wallis, Mann-Whitney U & Time to turn on the rod $1 H_{(2)}=9.60, p<0.001$ \\
\hline Figure $5 B$ & Non-normal distribution & Kruskal-Wallis & $H_{(2)}=3.07, p=0.216$ \\
\hline Figure $5 C$ & Normal distribution & One-way ANOVA & $F_{(2,25)}=2.77, p=0.082$ \\
\hline Figure $5 D$ & Normal distribution & One-way ANOVA & $F_{(2,22)}=1.44, p=0.259$ \\
\hline Figure $5 E$ & Normal distribution & One-way ANOVA, Tukey's HSD & $F_{(2,25)}=3.99, p=0.031$ \\
\hline Figure $5 F$ & Normal distribution & One-way ANOVA & $F_{(2,19)}=1.94, p=0.172$ \\
\hline Figure $5 G$ & Normal distribution & Two-way RM ANOVA & Genotype $\times$ time interaction $F_{(46,529)}=1.10, p=0.314$ \\
\hline Figure $5 \mathrm{H}$ & Normal distribution & Two-way RM ANOVA & Genotype $\times$ time interaction $F_{(46,460)}=0.65, p=0.964$ \\
\hline Figure 5/ & Normal distribution & Two-way RM ANOVA & Trials 1-9 $F_{(16,176)}=0.57, p=0.905$, trials $10-15 F_{(10,110)}=0.39, p=0.947$ \\
\hline Figure $5 J$ & Non-normal distribution & Kruskal-Wallis & Trial I $H_{(2)}=0.044 p=0.978$, Trial II $H_{(2)}=0.244 p=0.885$ \\
\hline Figure $6 A$ & Normal distribution & Two-tailed $t$ test & $t_{(13)}=1.59, p=0.137$ \\
\hline Figure $6 B$ & Normal distribution & One-way ANOVA, Tukey's HSD & $\begin{array}{l}\text { Atf } \alpha F_{(2,12)}=3.42, p=0.067 ; \text { Atf4 } F_{(2,12)}=7.76 p=0.007 ; \text { Chop } F_{(2,12)}= \\
\quad 3.72, p=0.056 ; \operatorname{Grp78} F_{(2,12)}=13.05, p=0.001 ; \operatorname{sXbp} 1 F_{(2,12)}=17.85 \\
\quad p=0.003 ; \operatorname{tXbp} 1 F_{(2,12)}=19.42, p=0.002 ; B c / 10 F_{(2,14)}=1.84, p= \\
\quad 0.196\end{array}$ \\
\hline Figure $6 C$ & Normal distribution & Two-way ANOVA, Tukey's multiple comparison & Genotype $\times$ treatment interaction $F_{(4,36)}=2.82, p=0.039$ \\
\hline Figure $6 D-K$ & Normal distribution & Two-way ANOVA, Tukey's multiple comparison & $\begin{array}{c}\text { Genotype } \times \text { treatment interactions: Atf6 } \alpha F_{(2,20)}=0.40, p=0.677 ; \text { Atf4 } \\
F_{(2,20)}=1.40, p=0.270 ; \text { Chop } F_{(2,20)}=0.07, p=0.934 ; \operatorname{Grp} 78 F_{(2,20)}= \\
0.71, p=0.504 ; \text { sXbp1 } F_{(2,18)}=5.73, p=0.012 ; \text { tXbp } 1 F_{(2,20)}=0.19, p= \\
0.826 ; \text { Bc/10 } F_{(2,20)}=1.72, p=0.203, \text { Txnip } F_{(2,16)}=1.40, p=0.275\end{array}$ \\
\hline Figure $6 M$ & Normal distribution & Two-way ANOVA & $\begin{array}{l}\text { Genotype } \times \text { treatment interactions: } \mathrm{p}-\mathrm{NF}-\kappa \mathrm{B} / \mathrm{NF}-\kappa \mathrm{B} F_{(1,14)}=1.698, p= \\
\quad 0.214\end{array}$ \\
\hline
\end{tabular}

examined the expression of UPR-related genes in the brains of both conventional Manf ${ }^{/-}$and conditional Manf $f^{f / f l}:$ : Nestin ${ }^{\mathrm{Cre} /+} \mathrm{KO}$ mice. The studied UPR-related genes were selected from all three UPR branches in addition to the major UPR sensor GRP78 (alias BiP), which in normal conditions binds to these ER transmembrane UPR transducers but dissociates when misfolded proteins start to accumulate in the ER (Lee, 2005).

First, the GPCR analysis performed on cDNA from the brains of $\mathrm{Manf}^{+/+}$and $\mathrm{Manf}^{/-}$mice indicated that the mRNA levels of all the UPR-related genes from three UPR pathways, Atf4, Atf $6 \alpha$, C/EBP homologous protein (Chop), Grp78, sXbp1 (activated by IRE1 $\alpha$ endoribonuclease activity), and total Xbp1 (tXbp1), were upregulated in the embryonic E13.5 Manf $^{/-}$mice brains and postnatally in the brains from newborn and two-week-old Manf $^{-/}$ mice (Fig. 2A; Table 1). Next, the UPR induction was analyzed in the brain tissue of five-week-old $\mathrm{Manf}^{\prime-}$ mice at the age of manifestation of high blood glucose levels and diabetes (Lindahl et al., 2014). The brain regions analyzed were the cortex, striatum, hippocampus, $\mathrm{SN}$ and cerebellum. The Atf6 $\alpha$ mRNA levels were not increased in any brain region analyzed from five-week-old Manf $^{\prime-}$ mice (Fig. 2B; Table 1). However, mRNAs encoding for Chop and Atf4, which are synthesized and activated despite the translational initiation block in the PERK pathway, were both upregulated in the cortex of $\mathrm{Manf}^{-1}$ mice (Fig. 2B; Table 1). Interestingly, mRNA levels of the spliced form of a transcription factor XBP1 (sXbp1) were significantly upregulated by 6.1 - to 11.5 -fold in the cortex, striatum, $\mathrm{SN}$, and cerebellum, indicating the activation of the IRE $1 \alpha$ signaling pathway (Fig. 2B; Table 1). In addition to sXbp1, 


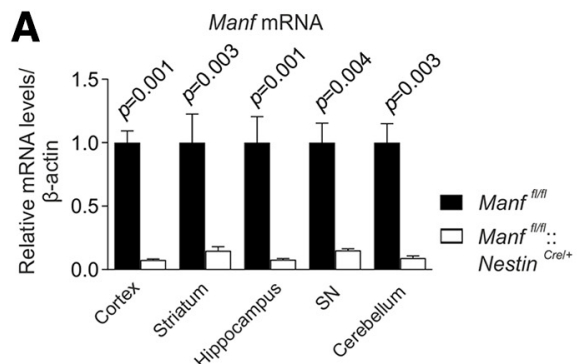

B ManfmRNA

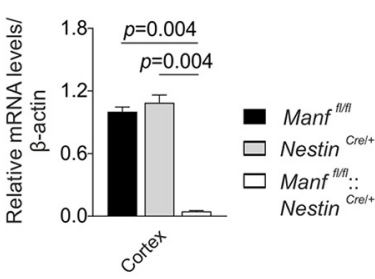

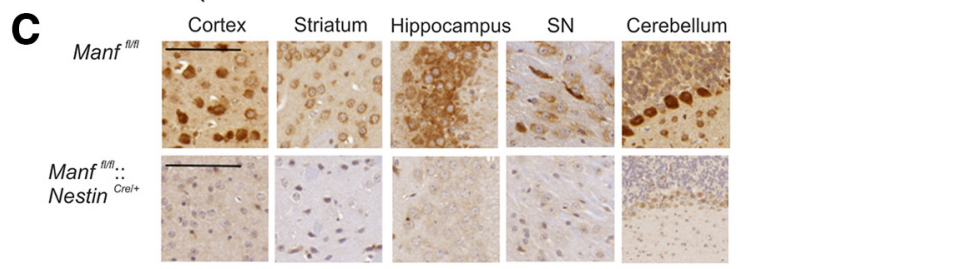
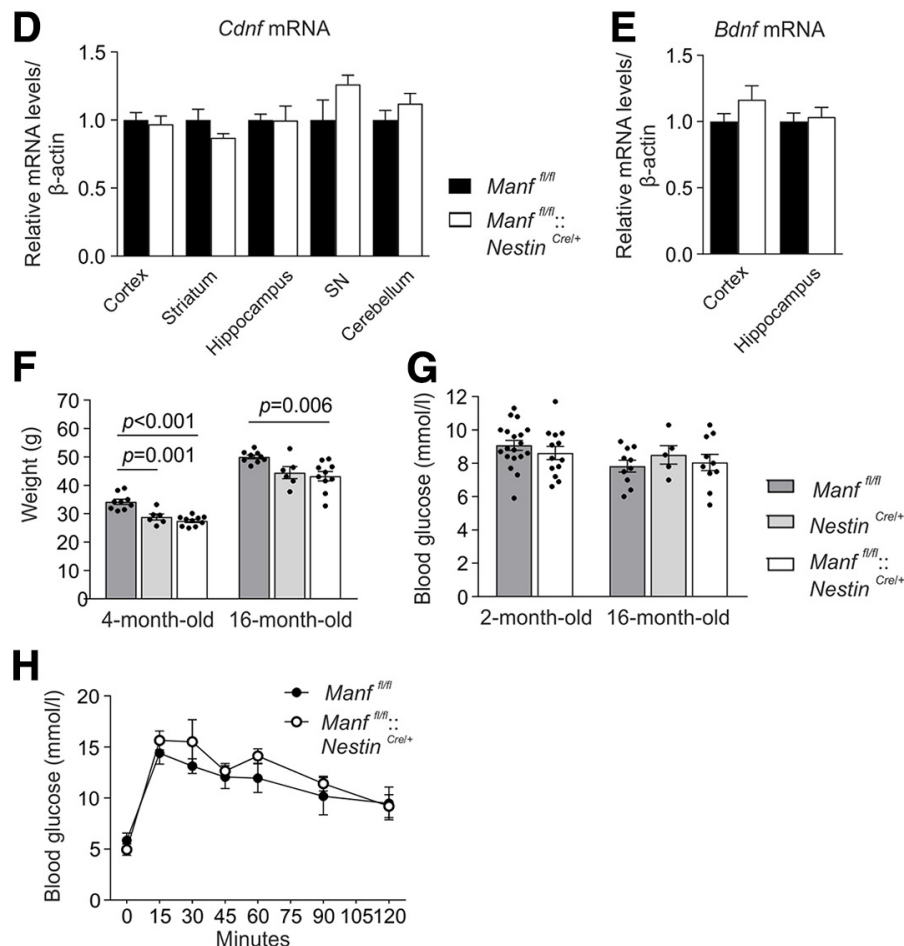

Figure 1. Generation of CNS-specific MANF KO mice. A, Manf mRNA levels in different brain areas of two-month-old Manf $f^{f l / f l}$ and Manff/ffl::Nestin $^{\mathrm{Cre} /+}$ female mice determined by qPCR $(n=4-9)$. Results are scaled to the average value of the control samples. $\boldsymbol{B}$, Manf mRNA levels of 16-month-old Manf ${ }^{f \mid f l}$, Manf $f^{f / f l}::$ Nestin $^{\mathrm{Cre} /+}$, and Nestin ${ }^{\mathrm{Cre} /+}$ male mice $(n=5-6)$. C, Immunoreactivity for endogenous MANF with hematoxylin counterstaining in the brains of Manf ${ }^{f / f l}$ and Manf ${ }^{f l / f l}:: N e s t i n^{C r e /+}$ mice. Scale bar: $200 \mu m$. D, Cdnf mRNA levels in different brain areas of two-month-old female mice $(n=4-9)$. $\boldsymbol{E}$, Bdnf mRNA levels in the cortex and hippocampus of two-month-old female mice $(n=6-8)$. F. Weights measured from Manff//fl. Manf $f^{f / f l}:: \mathrm{Nestin}^{\mathrm{Cre} /+}$, and Nestin ${ }^{\mathrm{Cre} /+}$ male mice at the age of four and 16 months $(n=6-14)$. G. Blood glucose levels of Manf $f^{f / f l}:: N e s t i n^{C r e /+}$ female and male mice and their littermate controls $(n=3-10)$. $\boldsymbol{H}$, Glucose tolerance test performed for 16-month-old Manf $f^{f / f l}$ and Manf $f^{f l / f l}:: N e s t i n^{C r e /+}$ female mice $(n=5)$. Mann-Whitney $U$ test, Student's $t$ test, one-way and two-way ANOVA followed by Tukey's post hoc test, or Kruskal-Wallis followed by Mann-Whitney $U$ test were used for statistical analysis. Data are presented as mean \pm SEM.

the mRNA levels of Grp78 were significantly increased in all examined brain areas of five-week-old Manf $^{\prime-}$ mice.

As experimentally-induced hyperglycemia and high-fat diet induced diabetes have been shown to increase ER stress and UPR activation in rodent brains (Zhao et al., 2015; Sims-Robinson et al., 2016), we studied the effect of MANF removal devoid of the hyperglycaemic effect in the brain tissue of Manf $f^{f / f l}::$ Nestin ${ }^{\text {Cre/+ }}$ mice. We examined UPR-related gene expression in the same brain regions of two-month-old Manf $f^{f / f l}:: \mathrm{Nestin}^{\mathrm{Cre} /+}$ mice and their Manf $f^{f / f f l}$ littermates. The increase in Xbp1 splicing in Manf ${ }^{f / f f l}:: N e s t i{ }^{C r e /+}$ mice varied between brain regions, there was a 4.7-fold increase in the cortex, 3.7fold increase in the striatum, 7.1-fold increase in the 

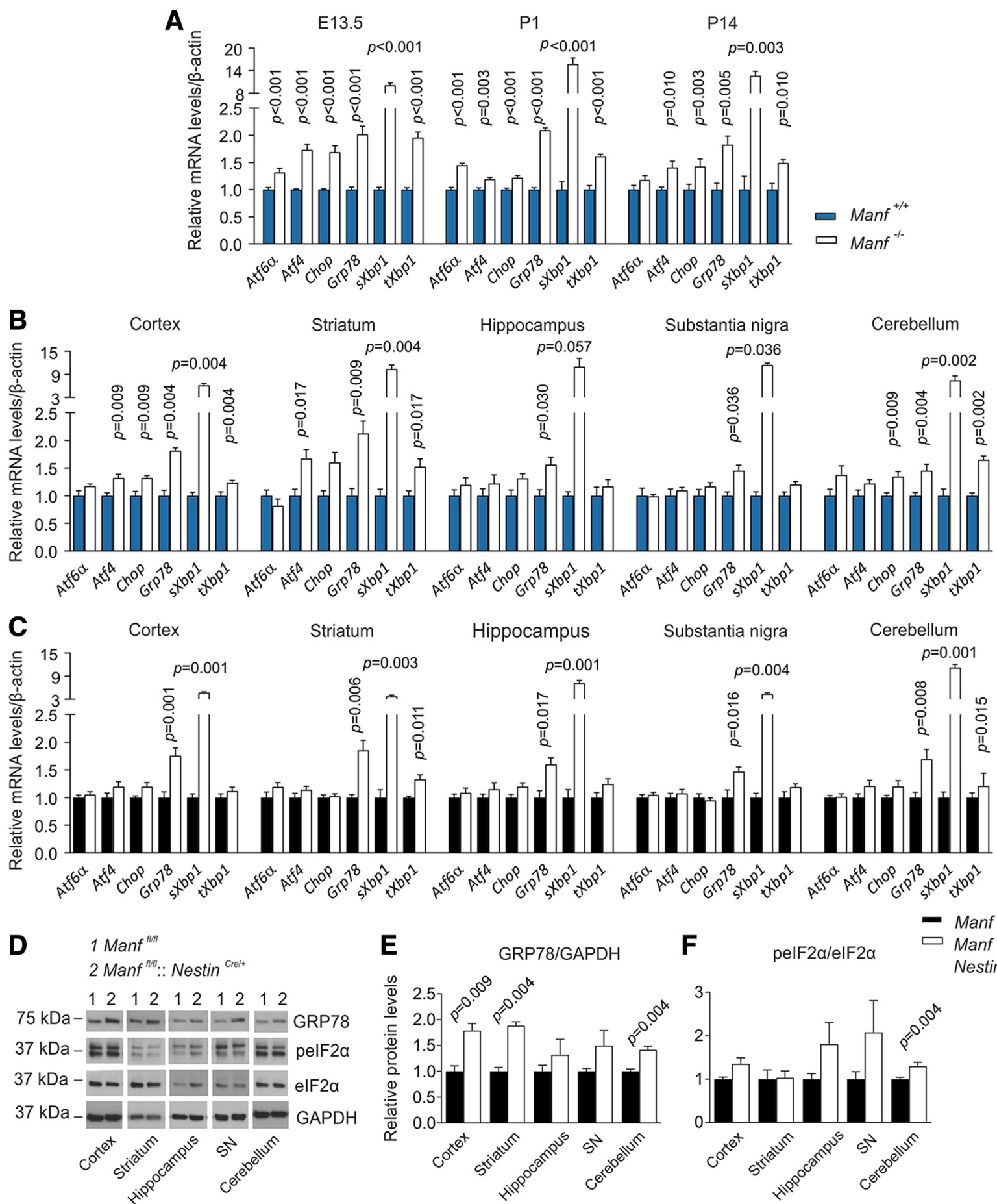

Striatum Hippocampus

$p=0.003$ $p=0.001$
Substantia nigra

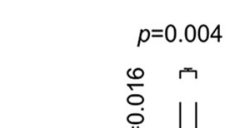

Cerebellum $p=0.001$ 而

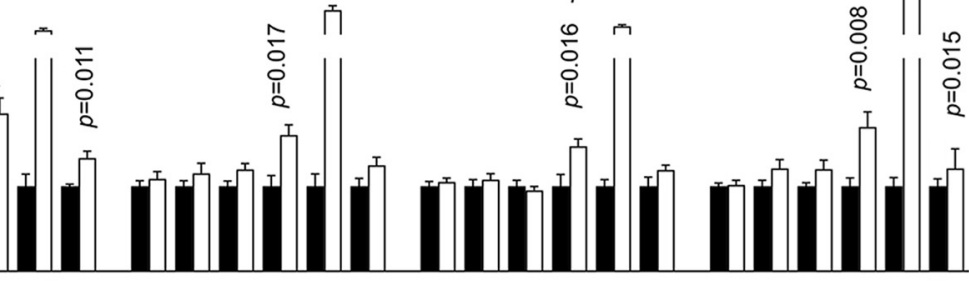

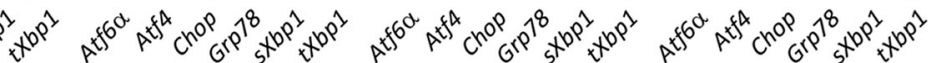

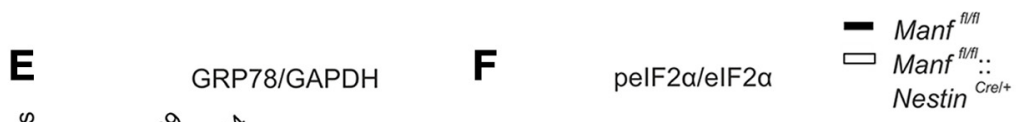

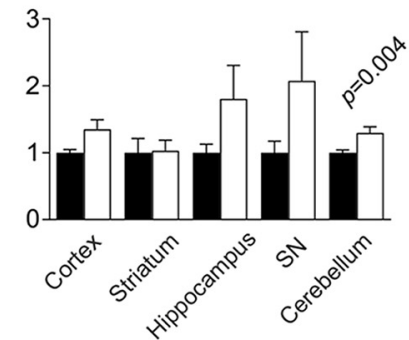
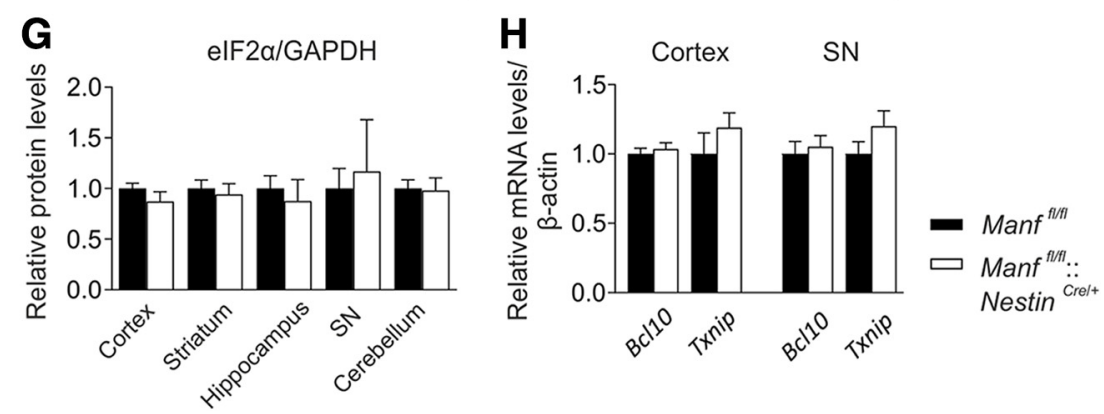
continued

Figure 2. Upregulation of UPR genes in the brains of both conventional and conditional MANF KO mice. $\boldsymbol{A}$, qPCR analysis of UPR genes in the brains of E13.5 embryos and P1 and P14 pups of Manf $^{/-}$and Manf ${ }^{+/+}$mice $(n=5-9)$. B, qPCR analysis of UPR markers in specific brain regions of five-week-old Manf $^{\prime-}$ and Manf $^{+/+}$female mice $(n=3-6)$. C, qPCR analysis detecting changes of UPR markers in different brain parts of two-month-old Manf ${ }^{f / f l}:: N e s t i n^{C r e /+}$ female mice and Manf fl/fl female littermates $(n=4-9)$. $\boldsymbol{D}$, Representative Western blottings of brain homogenates comparing protein levels of GRP78, p-elF2 $\alpha$, elF2 $\alpha$, and GAPDH between Manf $^{f / / f l}::$ Nestin $^{\mathrm{Cre} /+}$ and Manf $f^{f / f l}$ male mice. Optical density-based quantitation of protein levels in immunoblots, where GRP78 is normalized to GAPDH $(\boldsymbol{E})$, p-elF2 $\alpha$ to elF2 $\alpha(\boldsymbol{F})$, and elF2 $\alpha$ to GAPDH $(\boldsymbol{G} ; n=4-6)$. $\boldsymbol{H}$, mRNA levels of $B c / 10$ and Txnip in the cortex and SN of two-month-old Manf ${ }^{f / f f}:: N e s t i n^{C r e /+}$ and Manf ${ }^{f / f l}$ female mice $(n=4-8)$. Results are scaled to the average value of the control samples. Mann-Whitney $U$ test or Student's $t$ test was used for statistical analysis. Data are expressed as mean \pm SEM.

hippocampus, 4.4-fold increase in the $\mathrm{SN}$, and as much as an 11.2-fold increase in the cerebellum (Fig. 2C; Table 1). In addition, mRNA levels of Grp78 were significantly increased in all brain regions studied. Thus, upregulation of UPR genes Grp78 and sXbp1 was shared between conventional Manf $^{\prime-}$ mice and conditional Manff//fl::Nestin ${ }^{\text {Cre/+ }}$ mice, confirming that this is a phenotype caused by MANF deficiency and not diabetes.

Next, we estimated protein levels of two ER stress markers, GRP78 and phosphorylated eukaryotic translation initiation factor $2 \alpha$ (p-elF2 $\alpha$ ), in the brain homogenates of Manf $f^{f / f f l}$ and Manf $f^{\prime / f l}::$ Nestin ${ }^{\text {Cre/+ }}$ mice. During ER stress, activation of PERK results in phosphorylation of elF2 $\alpha$, leading to global translational repression (Walter and Ron, 2011). Results showed that the protein levels of GRP78 were significantly increased in the cortex, striatum and cerebellum (Fig. 2D,E; Table 1). Furthermore, the phosphorylation of elF2 $\alpha$ was significantly increased in the cerebellum, suggesting activation of the PERK pathway as well (Fig. $2 D, F$ ), but the expression of elF2 $\alpha$ was not increased (Fig. 2D,G). Despite the increase in the phosphorylation of elF2 $\alpha$, the mRNA levels of Atf 4 were not upregulated in conditional Manf $f^{f / f l}:: \mathrm{Nestin}^{\mathrm{Cre} /+}$ brain.

In addition to its endoribonuclease (RNase) activity, IRE $1 \alpha$ has a kinase activity that in ER stress, is responsible for recruitment of TRAF2 and further activation of the pro-inflammatory pathway, the nuclear factor $\kappa$ subunit (NF- $\kappa$ B; Walter and Ron, 2011; Tam et al., 2012). Recently, it was shown that exogenously added MANF reduces activation NF- $\kappa$ B pathway and downregulates Bcell lymphoma 10 (BCL10) mRNA expression in cytokinetreated human pancreatic islets in vitro (Hakonen et al., 2018). BCL10 is a pro-apoptotic protein and an upstream regulator of the NF- $\kappa \mathrm{B}$ pathway (Ruland et al., 2001). Silencing of MANF in a cytokine-treated human $\beta$ cell line results in an increase of BCL10 mRNA expression (Hakonen et al., 2018). Therefore, we also analyzed the mRNA levels of $B c / 10$ in Manf $f^{f / / f l}:: N e s t i{ }^{C r e /+}$ mice. However, we did not see changes in the expression levels of $\mathrm{Bc} / 10$ mRNA in the cortex and SN of Manff fl/fl::Nestin ${ }^{\text {Cre/+ }}$ mice compared with Manf $f^{f / f l}$ mice (Fig. $2 H$; Table 1).

Activation of IRE $1 \alpha$ RNase activity has been shown to induce expression of thioredoxin interacting protein (Txnip) by degradation of Txnip mRNA destabilizing miRNA-17 (Lerner et al., 2012). TXNIP expression has been associated with guiding $\beta$ cells to terminal UPR following IRE $1 \alpha$ hyperphosphorylation, oligomerization and increased inflammatory signaling (Morita et al., 2017). Therefore, we measured the mRNA levels of Txnip, but results showed no changes in the levels of Txnip mRNA expression in the cortex or SN of two-month-old Manf $f^{f \mid / f l}:$ : Nestin $^{\text {Cre/+ }}$ mice (Fig. 2H; Table 1).

\section{All three UPR pathways are activated in MANF- deficient mouse brain during aging}

To examine whether UPR activation continues during aging, we analyzed UPR genes in the cortex and SN of 16-month-old Manf ${ }^{f / / f l}:: N e s t i n^{C r e /+}$ mice. Similarly to the two-month-old mice, both Grp78 and sXbp1 mRNA levels were almost identically upregulated in the cortex of 16month-old mice (Fig. $3 A$; Table 1). This time, also Nestin ${ }^{\mathrm{Cre} /+}$ mice were included as another control, but the results showed similar mRNA levels between Manf $f^{f / f l}$ and Nestin ${ }^{\mathrm{Cre} /+}$ mice. Interestingly, in the SN of 16-month-old Manf $^{f / / f l}:: \mathrm{Nestin}^{\mathrm{Cre} /+}$ mice, expression of Atf6 $\alpha$ and Atf4 was also upregulated when compared with control mice, indicating activation of the ATF6 and PERK pathways in addition to the IRE1 $\alpha$ pathway (Fig. 3B; Table 1). In comparison with the situation in younger mice, when only the IRE1 $\alpha$ pathway was activated, 16-month-old Manf ${ }^{f / f}::$ Nestin $^{\text {Cre/ }+}$ mice had all three UPR pathways activated in the SN.

We also analyzed mRNA levels of both $\mathrm{Bc} / 10$ and Txnip in the SN of 16-month-old Manffl/fll Nestin $^{\mathrm{Cre} /+}$ and Manf ${ }^{f / l}$ ${ }^{f l}::$ Nestin ${ }^{\text {Cre/+ }}$ mice. These markers, however, had still not changed (Fig. 3C; Table 1). Finally, GRP78 expression was confirmed to localize to TH-positive dopamine neurons in the SN of Manf ${ }^{f / f l}$ and Manf ${ }^{f / f l}::$ Nestin ${ }^{\text {Cre/+ }}$ mice by immunohistochemical costaining of GRP78 and TH (Fig. 3D).

\section{MANF deficiency does not affect the number of midbrain dopamine neurons during ageing}

Previous studies have implied that chronic UPR activation has an impact on neuronal survival in the brain as ER stress is associated with neurodegeneration (Hetz and Saxena, 2017; Lindholm et al., 2017). Thus, the chronic ER stress found in the brains of Manffl/fl::Nestin ${ }^{\text {Cre/+ }}$ mice would indicate decreased survival, degeneration, and loss of neurons in the brains of these mice. Furthermore, MANF has been shown to be expressed in a portion of the TH-positive neurons in the SNpc (Lindholm et al., 2008) and therefore could affect their maintenance. To investigate the role of MANF as a physiological trophic factor for midbrain dopamine neurons, we analyzed the number of surviving nigrostriatal dopamine neurons of mice lacking endogenous MANF in the brain. Dopamine neurons in the $\mathrm{SNpc}$ were visualized by immunoreactivity to $\mathrm{TH}$, a rate-limiting enzyme in dopamine synthesis. Relative quantification of $\mathrm{TH}$-stained neurons in the SNpc showed no loss of 


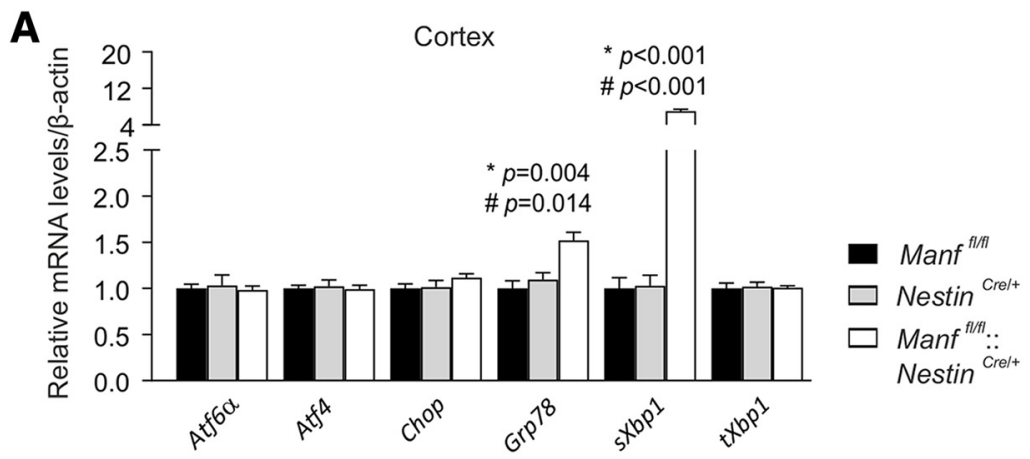

B
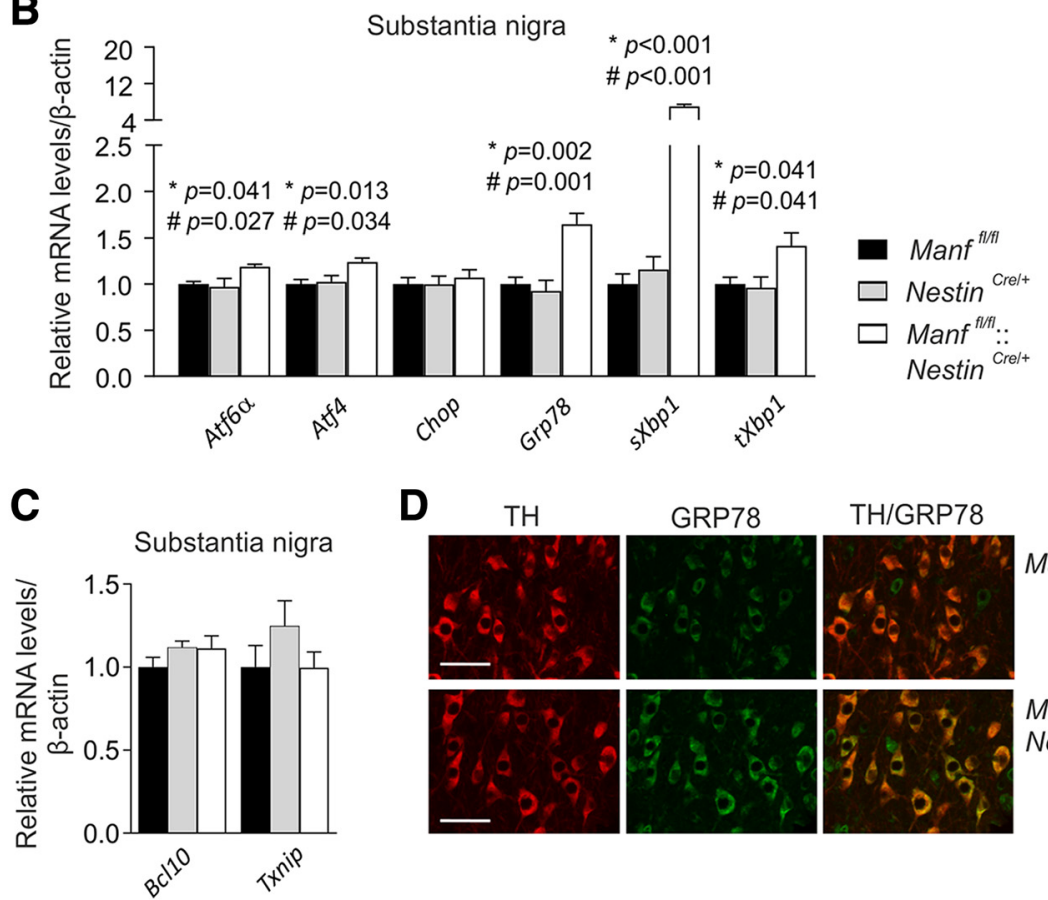

D $\mathrm{TH}$
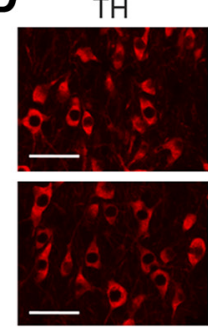

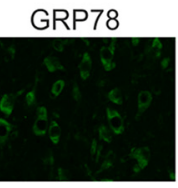

TH/GRP78

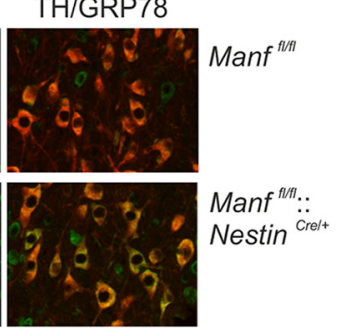

Figure 3. UPR remains activated in the brains of conditional MANF KO mice during aging. $\boldsymbol{A}$, qPCR analysis of UPR gene expression in the cortex samples of 16-month-old Manf ${ }^{f l / f l}:: N e s t i n^{C r e /+}, M_{a n f}^{f l / f l}$, and Nestin ${ }^{C r e /+}$ male mice $(n=5-6)$. B, Similar analysis of the SN from 16-month-old male mice $(n=4-5)$. C, mRNA levels of Bc/10 and Txnip measured from the SN of 16-month-old Manf $f^{f / f I}:$. Nestin ${ }^{\mathrm{Cre} /+}$, Manffl/fl $^{f}$, and Nestin ${ }^{\mathrm{Cre} /+}$ male mice $(n=4-6)$. D. Co-localization of TH and GRP78 in the SN of Manf ${ }^{f / f l}:: \mathrm{Nestin}^{\mathrm{Cre} /+}$ and Manfflffl female mice. Scale bar: $50 \mu \mathrm{m}$. Results are scaled to the average value of the control samples. One-way ANOVA followed by Tukey's post hoc test was used for statistical analysis. Data are expressed as mean \pm SEM; *p Manf ${ }^{f / f l}$ versus Manf ${ }^{f / / f I}:$ : Nestin ${ }^{\mathrm{Cre} /+}$, and \#p Nestin ${ }^{\mathrm{Cre} /+}$ versus Manf fl/fl::Nestin Cre/+

dopamine neurons in one-year-old Manf ${ }^{f l / f l}:: N e s t i n^{\mathrm{Cre} /+}$ mice (Fig. 4A; Table 1). The axonal branches and striatal terminals of nigral neurons were detected by immunostaining of striatal sections with antibodies detecting $\mathrm{TH}$ and dopamine transporter (DAT; Fig. 4B). Optical densities of TH-positive and DAT-positive staining in the dorsal striatum were not altered, indicating no detectable changes in the striatal innervation of nigral dopamine neurons in one-year-old Manf $f^{f / f l}:$ : Nestin ${ }^{\mathrm{Cre} /+}$ mice (Fig. 4C; Table 1). Moreover, we stained coronal brain sections including cortex and striatum with a neuronal NeuN antibody, but no obvious changes in the structure or number of positive cells were observed between one-year-old Manf ${ }^{f l / f l}::$ Nestin $^{\mathrm{Cre} /+}$ and Manff/ffl mice (Fig. 4D).

In addition to morphology, striatal monoamine levels were measured to examine possible changes in the activity of dopamine neurons. The levels of dopamine and its metabolites, DOPAC and HVA, were measured from the striatal samples of 16-month-old mice by HPLC, i.e., at the time when all three UPR pathways are activated in MANFdeficient mice. The results showed no differences in the production of dopamine or its metabolites between Manf ${ }^{f l f l}$ and Manf fl/fl::Nestin $^{\mathrm{Cre} /+}$ mice (Fig. 4E; Table 1). Unexpectedly, $\mathrm{Nestin}^{\mathrm{Cre} /+}$ mice had significantly elevated dopamine levels when compared with Manf $f^{f l f l}::$ Nestin ${ }^{C r e /+}$ mice, but there were no differences in the levels of DOPAC or HVA. Moreover, the levels of serotonin (5-hydroxytryptamine) and its metabolite 5-hydroxyindoleacetic acid were measured, and as a result, no differences were observed between the groups (Fig. 4E; Table 1).

To assess possible changes in TH and DAT levels, we studied their expression at mRNA and protein levels. The mRNA levels of Th and Dat in the striatum and levels of Th 
A
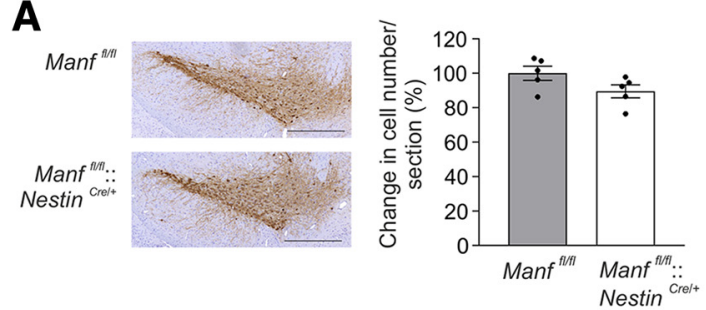

C
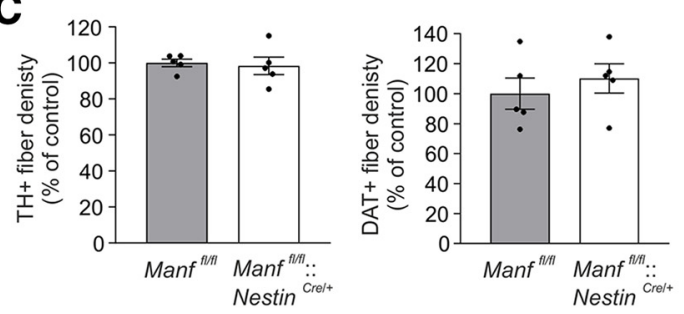

B

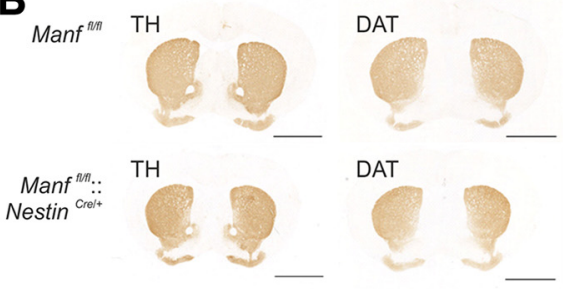

E

D
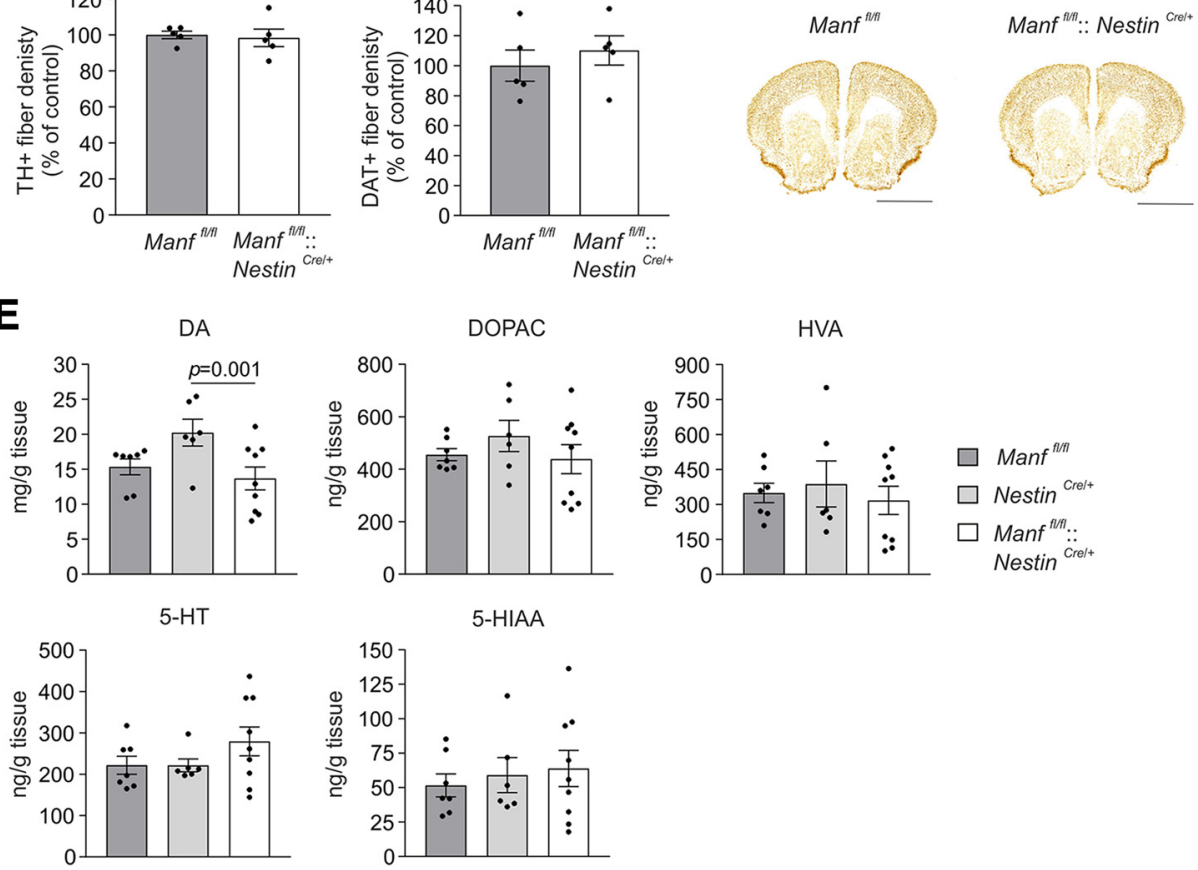

Figure 4. Loss of MANF in the brain does not cause degeneration of nigrostriatal dopamine neurons in vivo. A, Representative pictures of TH-stained coronal sections of the SNpc and quantification of dopamine neurons per section of the SNpc from one-yearold Manf ${ }^{f / f l}$ and Manff/fl::Nestin ${ }^{\text {Cre/+ }}$ female mice $(n=5)$. Scale bar: $500 \mu \mathrm{m}$. B, Representative figures of TH-immunoreactivity and DAT-immunoreactivity in coronal striatal sections. Scale bar: $2 \mathrm{~mm}$. $\boldsymbol{C}$, Measurement of optical density of TH-positive and DAT-positive dopamine fibers in one-year-old Manf ${ }^{f l / f l}:: N e s t i n^{C r e /+}$ female mice and their Manf $f^{f / f l}$ littermate controls $(n=5)$. $\boldsymbol{D}$, Representative NeuN-immunostaining in the sections from one-year-old Manf $f^{f / f l}$ and Manf ${ }^{f / f l}::$ Nestin ${ }^{C r e /+}$ female mice. Scale bar: 2 mm. E, HPLC analysis of monoamine metabolites measured from striatal samples of 16-month-old male mice $(n=6-8)$. DA, dopamine; DOPAC, 3,4-dihydroxyphenylacetic acid; HVA, homovanillic acid; 5-HIAA, 5-hydroxyindoleacetic acid; 5-HT, 5-hydroxytryptamine. For statistical analysis, the Student's $t$ test and Kruskal-Wallis test followed by Mann-Whitney $U$ test were used. Data are presented as mean \pm SEM. See Extended Data Figure 4-1 for the further measurement of TH and DAT mRNA and protein levels in the striatum and SN.

in the SN were analyzed by qPCR and the results showed no differences in the level of their expression between two-month-old Manf ${ }^{f / / f l}$ and Manf fl/ff::Nestin ${ }^{\text {Cre/ }+}$ mice (Extended Data Fig. 4-1A; Extended Data Table 1-1). Additionally, Western blot analysis indicated no changes in the protein levels of TH and DAT in the striatum or TH protein levels in the SN in Manf ${ }^{f / f l}::$ Nestin $^{\text {Cre/+ }}$ mice compared with control Manf $f^{f / f l}$ mice (Extended Data Fig. 41B,C; Extended Data Table 1-1). Thus, MANF deficiency does not affect the expression of TH or DAT in the midbrain of young adult mice.

\section{Mice lacking MANF in the brain exhibit normal motor behavior}

To investigate the effect of MANF absence from the nervous system on functional level, we characterized behavior of Manf $f^{f / f l}::$ Nestin ${ }^{\text {Cre/+ }}$ mice using a battery of different behavioral tests. The nigrostriatal pathway controls the initiation of movements and the cerebellum is important for the coordination of movements. Therefore, we analyzed motor behavior of MANF-deficient mice. Although the Nestin ${ }^{\mathrm{Cre} /+}$ line has been reported to have unaltered motor behavior, learning and memory, we still used this mouse line as a control, with Manf $f^{f / f l}$ littermate controls for Manf $f^{f / f t}::$ Nestin ${ }^{\mathrm{Cre} /+}$ mice (Giusti et al., 2014). Mice were tested at the age of four months and most tests were repeated in the same mice at the age of one year.

The performance in the multiple static rod test measuring balance was similar between four-month-old Manf ${ }^{f / / f l}$, Manf $^{f l / f l}: \mathrm{Nestin}^{\mathrm{Cre} /+}$ and Nestin ${ }^{\mathrm{Cre} /+}$ mice (Fig. 5A; Table 1). In the wire hanger test, all mice had a similar latency to fall, suggesting unaltered motor strength (Fig. 5B; Table 1). 

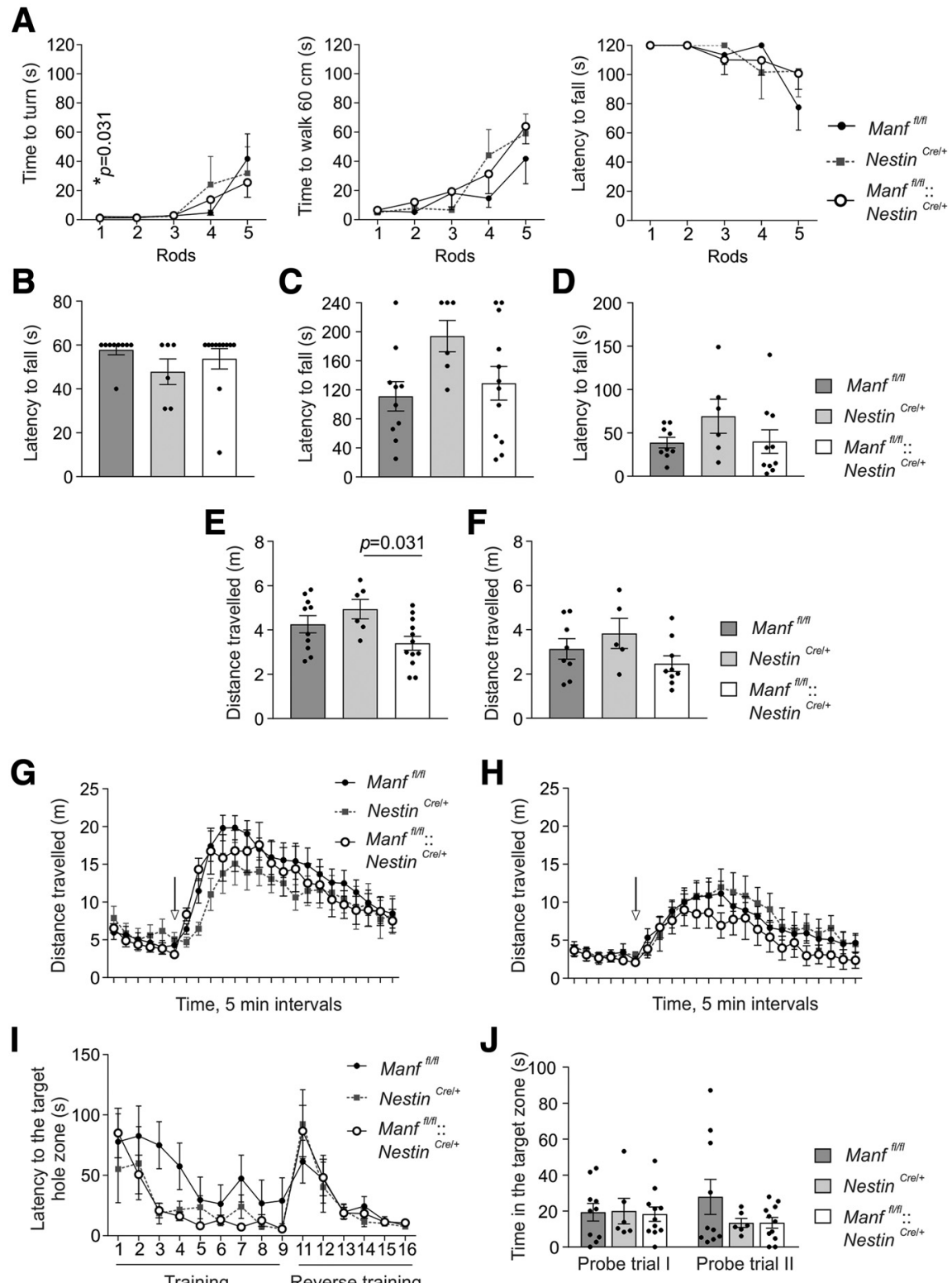

Figure 5. Lack of MANF causes no alterations in motor behavior, response to amphetamine, or learning and memory. A, Multiple static rod test showing time to turn, time to walk $60 \mathrm{~cm}$, and latency to fall using rods of different thickness from thicker (1) to thinner (5) in four-month-old Manf $f^{f l / f l}(n=10)$, Nestin $^{C r e /+}(n=6)$, and Manf $f^{f / f l}:: N e s t i n^{C r e /+}(n=11)$ mice. B, In the wire hanger test, latency to fall was measured in four-month-old $\operatorname{Manf}^{f / f f}(n=10)$, Nestin ${ }^{\mathrm{Cre} /+}(n=6)$, and Manf ${ }^{f l / f l}::$ Nestin ${ }^{\mathrm{Cre} /+}(n=11)$ mice. Latency to fall in an accelerating rotarod test in four-month-old Manffl/fl $(n=10)$, Nestin ${ }^{C r e /+}(n=6)$, and Manf $f^{f / f l}::$ Nestin $^{C r e /+}(n=12)$ mice $(\boldsymbol{C})$ and in oneyear-old Manf $f^{f / f l}(n=9)$, Nestin $^{\text {Cre/+ }}(n=6)$, and Manf $f^{f / f l}::$ Nestin ${ }^{\text {Cre/+ }}(n=10)$ mice $(\boldsymbol{D})$. Spontaneous locomotor activity in an openfield arena monitored for $30 \mathrm{~min}$ in four-month-old Manf $f^{f / f l}(n=10)$, Nestin $^{\mathrm{Cre} /+}(n=6)$, and Manf $f^{f / f l}::$ Nestin $^{\mathrm{Cre} /+}(n=12)$ mice $(\boldsymbol{E})$ and one-year-old Manf $f^{f / f l}(n=8)$, Nestin $^{\mathrm{Cre} /+}(n=5)$, and Manf ${ }^{f / / f l}:: N e s t i n^{\mathrm{Cre} /+}(n=9)$ mice $(\boldsymbol{F})$. Hyperactivity response following amphetamine administration (3 mg/kg, i.p.) after habituation in four-month-old Manf $f^{f / f l}(n=10)$, Nestin Cre/+ $(n=6)$, and Manf ${ }^{f / f l}::$ Nestin $^{\text {Cre/+ }}$ $(n=11)$ mice $(\boldsymbol{G})$ and in 14-month-old Manf $f^{f / f l}(n=9)$, Nestin $^{\text {Cre/+ }}(n=6)$, and Manf $f^{f / f l}::$ Nestin ${ }^{\text {Cre/+ }}(n=9)$ mice $(\boldsymbol{H})$. The arrow points out the time of amphetamine injection. I, In the Barnes maze test, mice were subjected to nine training sessions prior to the first probe trial and six reverse training sessions before the second probe trial. Latency to find the target zone over training sessions is presented for four-month-old Manf $f^{f l / f l}(n=10)$, Nestin ${ }^{\mathrm{Cre} /+}(n=6)$, and Manff/ffl:Nestin ${ }^{\mathrm{Cre} /+}(n=11)$ mice. J, Time spent around the target hole zone is presented for the first and second probe trials of the Barnes maze test. All the mice used in the behavioral test were male mice. For statistical analysis, Kruskal-Wallis test, one-way ANOVA, and two-way repeated measures ANOVA followed by Tukey's post hoc test were used; *p Manf ${ }^{f / f l}$ versus Manf $f^{f / f l}:$ :Nestin ${ }^{C r e /+}$. Data are presented as mean \pm SEM. 
Furthermore, the accelerated rotarod test measuring motor learning and coordination showed no alterations in the behavior of four-month-old (Fig. 5C; Table 1) or 12-month-old Manf $^{\text {fl/fl }:: N e s t i n^{\text {Cre/+ }}}$ (Fig. 5D; Table 1) mice. To study the general locomotor activity, mice were placed in an open field and their activity monitored for $30 \mathrm{~min}$. As Figure $5 E$ illustrates, four-month-old Manf ${ }^{f / / f l}:: \mathrm{Nestin}^{\mathrm{Cre} /+}$ mice moved less than $\mathrm{Nestin}^{\mathrm{Cre} /+}$ mice, but there was no difference in activity compared with Manf ${ }^{f / f f}$ littermates (Table 1). Furthermore, there were no changes in the locomotor activity between 12-month-old mice either (Fig. 5F; Table 1).

The functionality of the dopamine system in Manf $f^{f|f|}$ :: Nestin ${ }^{\mathrm{Cre} /+}$ mice was analyzed by their responses to a dopaminergic stimulant. Amphetamine releases dopamine from vesicles in dopamine neurons and elevates striatal extracellular dopamine levels causing hyperactivity in mice (Yates et al., 2007). The response to D-amphetamine measured by locomotor activity was similar between Manf $f^{f / f /}:$ :: Nestin ${ }^{\mathrm{Cre} /+}$ and control mice at the age of four months (Fig. 5G; Table 1) and 14 months (Fig. 5H; Table 1), although the response to amphetamine was in general more modest in older mice. These results suggest that both dopamine uptake and release in the MANF-deficient striatum are normal.

Long-term memory formation relies on the synthesis of new mRNA and proteins, but in the case of ER stress, and particularly PERK pathway activation, protein translation is attenuated (Ohno, 2018). Indeed, hippocampal ER stress has been demonstrated to cause memory dysfunction (Zhang et al., 2014). Since we observed increased UPR activation in Manff f/ffl::Nestin ${ }^{\mathrm{Cre} /+}$ mice, we decided to investigate their spatial long-term memory by using the Barnes maze test, which consists of training trials and probe test trials measuring learning and long-term memory, respectively. In the second part of the test, the mice are trained to find the new location of the escape box to test behavioral flexibility. The results showed that fourmonth-old mice had a similar learning pattern independent of the genotype (Fig. 5/; Table 1) and we could not see differences between mice at one year of age either, indicating no alteration in learning (data not shown). In the memory test, the time spent in the target hole zone represents spatial long-term memory. The first and second probe trials for four-month-old mice showed that Manf fl/fl, Manffl/fl::Nestin ${ }^{\mathrm{Cre} /+}$, and Nestin ${ }^{\mathrm{Cre} /+}$ mice spent a similar amount of time in the target hole zone (Fig. 5J; Table 1) and similar behavior was observed for one-year-old mice (data not shown). Furthermore, there were no differences between genotype groups in any other of the parameters tested, which were latency to find the target hole zone, number of visits in the target hole zone, and errors made finding the target hole zone (data not shown). Thus, we found no defects in learning and long-term memory of Manf $^{f / / f l}::$ Nestin $^{\mathrm{Cre} /+}$ mice.

\section{Cultured cortical neurons from embryonic MANF KO mice show increased ER stress and vulnerability to chemically-induced ER stress}

To study the survival of MANF KO neurons in vitro, we isolated dopamine neurons from the midbrain floor of E13.5 $\mathrm{Manf}^{+/+}$and Manf ${ }^{--}$embryos and cultured them for $5 \mathrm{~d}$. The number of surviving TH-positive cells was measured by comparing the initial number of cells on DIV1 with the number of cells on day 5 . The results showed no changes in the survival of non-treated $\mathrm{TH}$ positive neurons from MANF KO mice compared with wild-type controls in vitro (Fig. 6A; Table 1).

Because of the scarce material obtained from a midbrain floor of one embryonic mouse, we could not plan controlled chemical treatments and biochemical analysis for MANF KO dopamine neurons. Therefore, we continued to study UPR activation in vitro using primary cortical neurons isolated from $\mathrm{Manf}^{+/+}, \mathrm{Manf}^{+/-}$, and $\mathrm{Manf}^{/-} \mathrm{em}$ bryos at day E16 or E17 as they can be easily obtained with large quantities from embryonic mice. First, we evaluated the ER stress levels of cortical neurons cultured for two weeks. The cultures consisted mostly of a heterogenic population of cortical neurons as they were treated with mitotic inhibitors to reduce non-neuronal cell proliferation. Increased UPR activation was found in $\mathrm{Manf}^{\prime-}$ cortical neurons when compared with neurons from both $\mathrm{Manf}^{+/+}$ and $\mathrm{Manf}^{+/-}$embryos. Similarly to increased expression of UPR genes in the brain of Manf ${ }^{/-}$embryos in vivo (Fig. $2 A$ ), expression of Grp78, sXbp1, and tXbp1, but not Chop and Atf6 $\alpha$, was increased in Manf ${ }^{-1}$ neurons cultured for $14 \mathrm{~d}$ in vitro (Fig. 6B; Table 1). In addition, the mRNA levels of Atf4 were increased, suggesting activation of the PERK pathway. The Bc/10 mRNA levels did not differ between genotypes (Fig. 6B; Table 1).

The vulnerability of Manf ${ }^{/-}$cortical neurons was assessed by applying a chemical ER stressor, thapsigargin, to the cultures. Thapsigargin blocks the sarcoendoplasmic reticulum calcium transport ATPase (SERCA) pump and depletes $\mathrm{Ca}^{2+}$ stores from the ER, leading to UPR activation and cell death in various cell types, including neurons ( $\mathrm{Li}$ and $\mathrm{Hu}, 2015)$. Thapsigargin at a concentration of $10 \mathrm{nM}$ for $48 \mathrm{~h}$ led to a $66.3 \pm 10.4 \%$ reduction in Manf $^{-/}$ neuronal survival compared with dimethyl sulfoxide (DMSO)-treated neurons, whereas the decrease in survival of control Manf ${ }^{+/+}$neurons was $34.9 \pm 7.9 \%$ and Manf $^{+/-}$neurons $37.1 \pm 13.4 \%$ (genotype-treatment interaction, $p=0.039$; Fig. $6 C$; Table 1). At $5 \mathrm{nM}$ thapsigargin, no changes in the number of surviving neurons were detected (Fig. 6C). As a result, neurons without endogenous MANF were more vulnerable to thapsigargin-induced ER stress in vitro.

To examine further the effect of thapsigargin on neuronal cultures, the expression of several UPR markers was analyzed after a 48-h-long exposure to $10 \mathrm{nM}$ thapsigargin. Upregulation of many UPR genes, Atf6 $\alpha$, Atf4, Chop, Grp78, sXbp1, and $t X b p 1$, was detected after thapsigargin treatment in all genotypes (Fig. 6D-l; Table 1). Furthermore, expression of $B c / 10$ was higher in thapsigargin-treated neurons compared with DMSO-treated ones (Fig. 6J; Table 1). The treatment with $10 \mathrm{nM}$ thapsigargin resulted in a significant genotype-treatment interaction only regarding mRNA levels of $s$ Xbp $1(p=0.012$; Table 1$)$. Thus, the results showed higher upregulation of $s \times b p 1$ in Manf $^{/-}$neurons compared with $\mathrm{Manf}^{+/+}$and Manf ${ }^{+/-}$neurons (Fig. 6H). We also measured the mRNA levels of Txnip in the samples, and the levels were upregulated in 
A

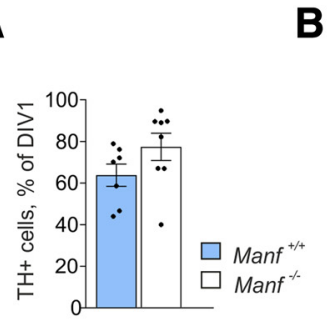

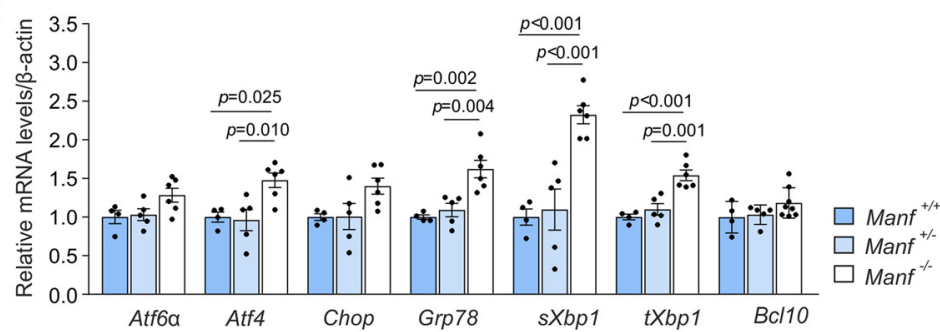
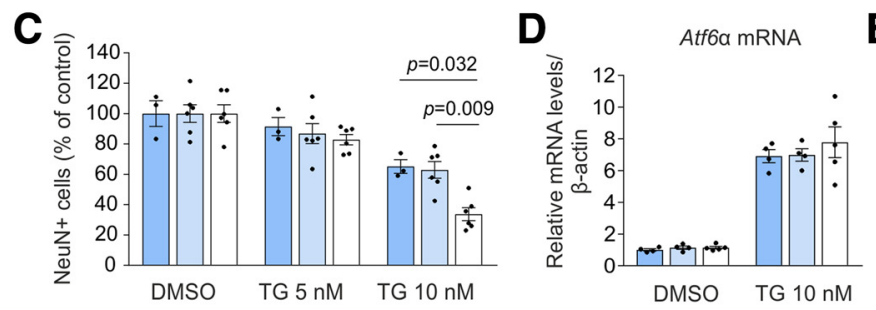

E

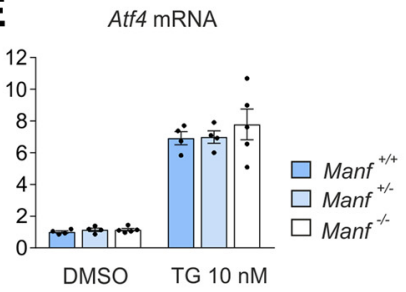

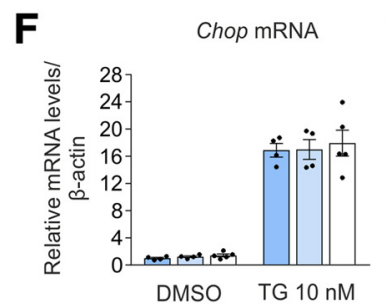
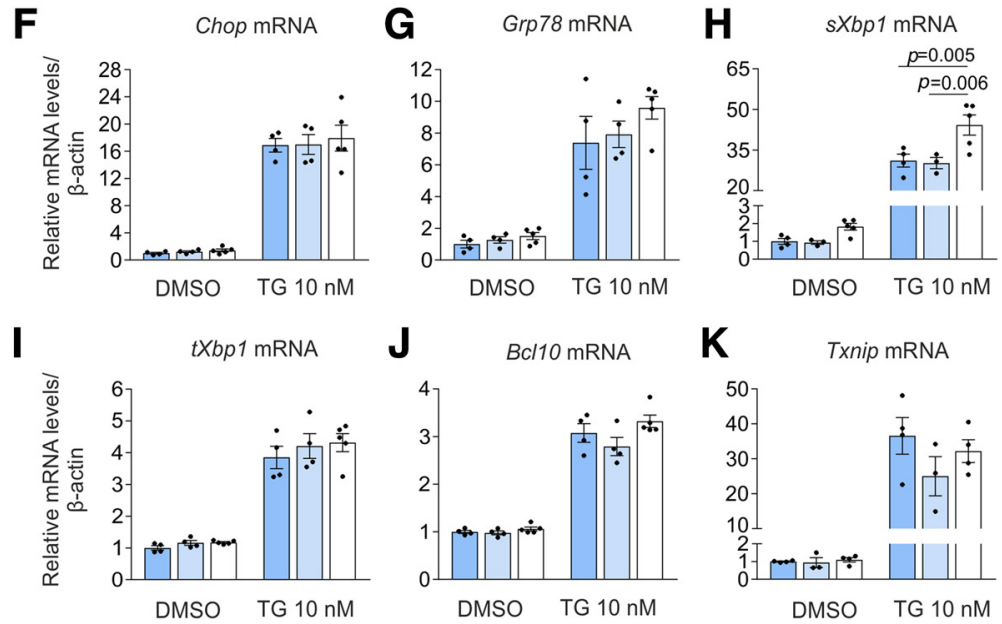

L

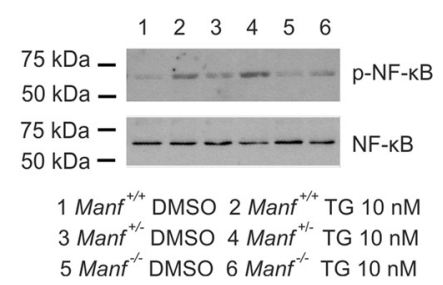

M

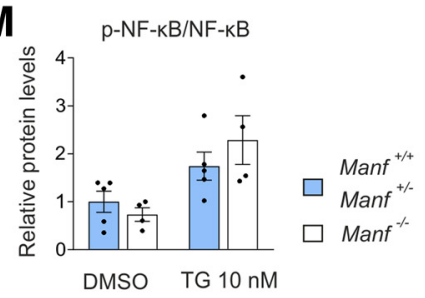

Figure 6. ER stress in embryonic cortical cultures of $\mathrm{Manf}^{\prime-}$ mice and their vulnerability to thapsigargin (TG). $\boldsymbol{A}$, Survival of embryonic midbrain dopamine neurons in vitro isolated from Manf ${ }^{+/+}$and Manf ${ }^{-1}$ mice $(n=7-8)$. B. Expression of UPR related and Bc/10 genes in $\mathrm{Manf}^{+/+}, \mathrm{Manf}^{+/-}$, and $\mathrm{Manf}^{/-}$cortical neurons cultured for $14 \mathrm{~d}$ and studied by qPCR $(n=4-8)$. C, Effect of the TG treatment on neuronal survival. Cortical neurons were treated with TG at DIV9, fixed after $48 \mathrm{~h}$, and stained with the NeuN antibody $(n=3-5)$. The loss of cells was quantified by comparing the neuron number with vehicle-treated cultures. Neurons were similarly treated with TG at DIV9, collected after $48 \mathrm{~h}$ and analyzed by qPCR for the expression of Aft6 $\alpha(\boldsymbol{D})$, Atf4 (E), Chop (F), Grp78 (G), sXbp1 $(\boldsymbol{H})$, tXbp1 (I), Bc/10 (J), and Txnip $(\boldsymbol{K})$ expression $(n=3-5)$. $\boldsymbol{L}$, Western blottings presenting phosphorylated NF- $\kappa$ B and NF$\kappa \mathrm{B}$ expression in $\mathrm{Manf}^{+/+}$, Manf $^{+/-}$, and Manf $^{/-}$cortical cultures after 48-h-long exposure to TG. M, Quantification of Western blottings, where $\mathrm{p}-\mathrm{NF}-\kappa \mathrm{B}$ is normalized to NF- $\kappa \mathrm{B}(n=4-5)$. Results are scaled to the average value of the control samples. Each data point represents one animal and its value is an average of at least two wells. Data are expressed as mean \pm SEM of at least three independent experiments. Experimental groups were compared by the Student's $t$ test, one-way ANOVA, or two-way ANOVA followed by Tukey's multiple comparison test.

response to thapsigargin but did not differ between the genotypes (Fig. 6K; Table 1).

Finally, as sustained ER stress is known to induce $\mathrm{NF}-\kappa \mathrm{B}$ activation by IRE $1 \alpha$ activation (Kaneko et al., 2003), we also evaluated the phosphorylation of NF- $\kappa$ B by Western blotting (Fig. 6L). Because of a small sample size, we combined $\mathrm{Manf}^{+/+}$and $\mathrm{Manf}^{+/-}$samples together. Quantification of intensity in Western blotting bands showed only a trend towards increased phosphorylation of $\mathrm{NF}-\kappa \mathrm{B}$ in $\mathrm{Manf}^{-/-}$neurons after $10 \mathrm{nM}$ 
thapsigargin treatment compared with that in control neurons (Fig. 6M; Table 1).

\section{Discussion}

In this study, we elucidate the previously unknown function of endogenous MANF in the mouse brain. Previous studies have suggested a function for MANF in the maintenance of neurons based on neuroprotective and neurorestorative effects of MANF in different rodent degenerative disease models (Airavaara et al., 2009; Voutilainen et al., 2009; Yang et al., 2014; Neves et al., 2016). However, our results indicate for the first time that endogenous MANF is not needed for the maintenance of midbrain dopamine neurons in mice. It has been implicated, that accumulation of misfolded or aggregated proteins followed by severe chronic UPR causes neuronal death in neurodegenerative diseases. This study, however, questions this present view and shows that sustained but moderate UPR in the rodent brain is not detrimental.

The phenotype of conventional $\mathrm{Manf}^{--}$is dominated by the development of insulin-dependent diabetes, a severe growth defect and premature death (Lindahl et al., 2014). On the contrary, Manf $f^{f l / f l}::$ Nestin $^{\mathrm{Cre} /+}$ mice are viable and have a normal lifespan without diabetes or gross defects, but adult Manf $f^{f l f l}:: N e s t i n^{C r e /+}$ mice have a decreased body weight when compared with littermate Manf ${ }^{f / f l}$ controls. In a recent study, Manf knock-down by siRNA from the hypothalamus resulted in hypophagia and reduced body weight (Yang et al., 2017), suggesting that Manf $f^{f / f l}:$ : Nestin ${ }^{\mathrm{Cre} /+}$ mice could be smaller due to hypophagia. However, Nestin $\mathrm{Cre/+}$ mice themselves have been reported with a growth defect due to reduced levels of mouse growth hormone (Galichet et al., 2010; Declercq et al., 2015). Therefore, the reduced weight in Manf ${ }^{f / f l}:$ : $\mathrm{Nestin}^{\mathrm{Cre} /+}$ mice is affected by the Nestin ${ }^{\mathrm{Cre} /+}$ transgene and the effect of hypothalamic MANF deficiency on food intake requires more investigations.

Upon ER stress, the IRE $1 \alpha$ receptor is autophosphorylated and its RNase activity leads to degradation of mRNAs and unconventional splicing of Xbp 1 mRNA (Walter and Ron, 2011). Our study reveals increased activation of the IRE $1 \alpha$ RNase pathway in the brains of both conventional $\mathrm{Manf}^{-/}$mice and conditional Manf ${ }^{f / f l}:$ : Nestin ${ }^{\mathrm{Cre} /+}$ mice. In young adult $\mathrm{Manf}^{-1}$ mice, UPR activation seems more severe with increased expression of Chop mRNA, which may be partially due to the manifestation of hyperglycemia as cerebral ER stress has been reported in diabetic mice (Zhao et al., 2015). Spliced XBP1 induces the expression of UPR target genes, such as Grp78 (Hetz and Saxena, 2017). Indeed, Grp78 expression is also increased in tissue samples where splicing of $X b p 1$ is elevated. The increased phosphorylation of elF2 $\alpha$ in the brains of Manf ${ }^{f / f f}::$ Nestin ${ }^{\mathrm{Cre} /+}$ mice does not result in increased expression of its downstream components Atf4 nor Chop indicating only minor PERK pathway activation at young age. However, in 16-month-old Manf $f^{f l f l}:$ : Nestin ${ }^{\mathrm{Cre} /+}$ mice, expression of Atf4 and Atf6 $\alpha$ are increased suggesting activation of both PERK and ATF6 pathways in the brain at older age. Interestingly, the IRE1 $\alpha$ RNase pathway is chronically stimulated through the lifespan of Manf ${ }^{f l / f l}::$ Nestin ${ }^{C r e /+}$ mice. Therefore, supporting previous findings in other tissues (Wang et al., 2018; Hartman et al., 2019), we conclude that also in neurons MANF regulates UPR mainly through the IRE $1 \alpha$ pathway.

In rats, exogenously added and striatally overexpressed MANF protects dopamine neurons in the 6-hydroxydopamine model of Parkinson's disease (Voutilainen et al., 2009; Hao et al., 2017). Here, we analyzed whether MANF deficiency and chronic UPR in the mouse brain leads to nigrostriatal neurodegeneration. It has been shown that in Parkinson's disease dopamine neurons start to degenerate by losing their synapses and axons. This is observed both in patients and in Parkinson's rodent disease models with clear Parkinson's disease phenotype (Domanskyi et al., 2015). In this study, we measured the optical density of striatal dopamine fibers by two different markers, $\mathrm{TH}$ and DAT, and did not observe any differences in density between the genotypes. We also used even more sensitive measurements for dopamine neuronal degeneration by quantifying striatal dopamine concentrations and its metabolite levels with HPLC, and did not find any differences between the genotypes. The concentrations of the striatal samples were in range of $7.6-25.4 \mathrm{mg} / \mathrm{g}$ of tissue, and similar that we have published before (Albert et al., 2019). Based on these results, maintenance of dopamine neurons is not affected by the embryonic onset of MANF deficiency in the mouse brain, which supports another study showing MANF not being a crucial survival factor for dopamine neurons in Caenorhabditis elegans (Hartman et al., 2019).

Synaptic alteration and loss occur at early stages of neurodegenerative diseases, such as Alzheimer's, Parkinson"s and Lewy body diseases (Hunn et al., 2015; Overk and Masliah, 2014). It has been demonstrated in mice that synapses can degenerate, although striatal dopamine fibers and dopamine levels stay unchanged (Galli et al., 2014). Therefore, in the future, it will be important to quantify the number of synapses (DeKosky and Scheff, 1990) and examine individual synapses of dopamine neurons in MANFdeficient mice using highly sensitive technologies, such as mass synaptometry (Gajera et al., 2019). Furthermore, changes in dopamine transmission at the synapses can also occur without dopamine neuron loss as shown in CDNF KO mice (Lindahl et al., 2020). Despite the unchanged response to amphetamine, detailed investigation of the dopamine neurotransmission in MANF-deficient mice would be justified in the future.

It is possible that embryonic deletion of MANF is compensated by factors that remain unknown. We confirmed that at least in the adult brain, loss of MANF is not compensated by its protein family member CDNF, but future studies on CDNF-MANF double $\mathrm{KO}$ mice are relevant. With possible functional compensation in mind, we also quantified the mRNA levels of Bdnf, Th, and Dat and protein levels of TH and DAT but found no changes in their levels between the genotypes. In future studies it will be important to eliminate embryonic compensatory effects in the MANF KO mice by deleting MANF specifically from the brain in adult mice. It has been shown that in ischemic brains, MANF is expressed in activated microglia (Shen et 
al., 2012). Other studies also demonstrate expression of MANF by myeloid cells (Neves et al., 2016; Mätlik et al., 2018). It is possible that MANF is expressed by microglia in our Manf ${ }^{f l / f l}:: N e s t i n^{C r e /+}$ mice. However, we did not find detectable levels of Manf mRNA expression in the cortex of 16-month-old Manf ${ }^{f / f l}:: N e s t i n^{C r e /+}$ mice suggesting no microglial upregulation of MANF.

Normal locomotor activity of Manf ${ }^{f l / f l}:: N e s t i n^{C r e /+}$ mice is in line with unaltered open field activity of $\mathrm{Manf}^{--}$mice (Lindahl et al., 2014). In Nestin ${ }^{\mathrm{Cre} /+}$ mice, slightly higher locomotor activity could be explained by their surprisingly higher striatal dopamine levels. However, this phenomenon might be due to differences in a genetic background as our breeding did not generate Nestin $\mathrm{Cre/+}$ littermate control mice alone. Although ER stress can impair longterm memory (Ohno, 2018), hippocampal sXBP1 overexpression, instead, has been shown to improve long-term memory through elevated Bdnf levels (Martínez et al., 2016). However, we did not observe changes in the hippocampal Bdnf mRNA levels in Manf fl/fl::Nestin Cre/+ mice possibly explaining the unchanged memory consolidation. Thus, despite increased expression of Grp78 and sXbp1 mRNA in the hippocampus of Manf $f^{f l / f l}::$ Nestin ${ }^{\mathrm{Cre} /+}$ mice, behavioral tests showed that MANF deficiency does not result in memory impairment.

We have shown that exogenously administered MANF before cerebral ischemia protects cortical neurons in rats (Airavaara et al., 2009) and poststroke delivery of MANF induces functional recovery of rats after cerebral ischemia (Mätlik et al., 2018). Moreover, the infarction size in the MANF-deficient brain is larger, indicating that endogenous MANF has a protective effect on cortical neurons against ischemic injury (Mätlik et al., 2018). Therefore, we examined ER stress in the $\mathrm{Manf}^{-1}$ primary cortical neurons. Cortical MANF KO neurons show increased ER stress levels, confirming that the increased UPR activation is neuronal. We also report decreased survival of thapsigargin-treated MANF-depleted cortical neurons, suggesting increased vulnerability of $\mathrm{Manf}^{--}$cortical neurons in vitro. Neurons in cortical cultures were quantified based on their immunoreactivity to NeuN, although we acknowledge the issues related to its use in primary cultures. It has been criticized that also astrocytes can show immunoreactivity to NeuN in vitro (Darlington et al., 2008) and that the loss of NeuN expression does not necessarily correlate with cell death (Unal-Cevik et al., 2004). Here, we used it as a marker for the vulnerability of neurons to chemically-induced ER stress comparing with untreated neurons.

Previously, we reported impairments in the cortical development of Manf $^{/-}$brain, but the adult cortex is morphologically normal (Tseng et al., 2017). Our results here show increased UPR activation in the brain of $\mathrm{Manf}^{-1}$ mice during embryonic and postnatal development, but activation seems to gradually decrease after birth. UPR has been shown to be tightly regulated during neurodevelopment and to play a critical role during maturation of neurons and in neurodevelopmental diseases (Laguesse et al., 2015; Godin et al., 2016; Gladwyn-Ng et al., 2018). Interestingly, a patient with a homozygous missense mutation in the MANF gene likely leading to a null mutation was presented with microcephaly and diabetes (Yavarna et al., 2015). Thus, the impact of MANF in the development of the human brain might differ compared with mice.

Whereas chronic UPR activation kills $\beta$ cells (Lindahl et al., 2014), neuronal loss is not observed in the midbrain of Manf $^{f l / f l}:$ :Nestin ${ }^{\mathrm{Cre} /+}$ mice. One of the actors determining the switch between adaptive and terminal UPR followed by IRE1 $\alpha$ activation is TXNIP (Anthony and Wek, 2012). However, in Manf $f^{f l / f l}:: N e s t i{ }^{C r e /+}$ mice midbrain the IRE1 $\alpha$ pathway is activated without increased expression of Txnip mRNA. One of the differences between $\beta$ cells and dopamine neurons is that $\beta$ cells produce and secrete insulin at a high rate, making them vulnerable to additional ER perturbation. Although chronic ER stress in $\beta$ cells leads to increased activation of the NF- $\kappa \mathrm{B}$ pathway (Danilova et al., 2019a), this pathway is not upregulated in neuronal tissue lacking MANF. As expression of $\mathrm{Bc} / 10$ mRNA or phosphorylation of NF- $\kappa$ B was not differently regulated between genotypes after thapsigargin administration, we suggest that the increased susceptibility of MANF KO neurons to thapsigargin is not related to the activation of the $\mathrm{NF}-\kappa \mathrm{B}$ pathway. We conclude that the IRE $1 \alpha$-TRAF2-NF- $\kappa$ B branch is not activated in MANFdeficient neurons.

A recent study suggests that MANF functions as a negative regulator of IRE1 and XBP1 activity in nematodes (Hartman et al., 2019). Our data demonstrating how ablation of Manf increases $S X b p 1$ levels agrees with this hypothesis. The IRE $1 \alpha-\mathrm{XBP} 1$ pathway is regarded as an UPR branch, which can, differently from others, also enhance cell viability (Lin et al., 2009). Activation of this pathway has also demonstrated neuroprotection in different in vivo models of CNS diseases (Ni et al., 2018). In the MPTPinduced animal model of Parkinson's disease, for example, expression of sXBP1 protects dopamine neurons (Sado et al., 2009). We can hypothesize that in our mouse model, neurons are adapted to constant, non-pathologic activation of the IRE $1 \alpha$ pathway increasing the capability to survive from the terminal UPR. Developmental deletion of XBP1 in the nervous system also causes ER stress in the mouse brain, which protects dopamine neurons, whereas reduction of XBP1 levels at the adult stage results in neurodegeneration (Valdés et al., 2014). The authors speculate that developmental adaptation to ER stress would explain the protection of dopamine neurons (Valdés et al., 2014). A similar adaptation might occur in our Manf ${ }^{f / f f}::$ Nestin ${ }^{\mathrm{Cre} /+}$ mice, and therefore, adult knock-down of Manf expression may lead to a deleterious outcome.

In conclusion, our study describes a mouse model with prolonged UPR activation in the brain. We discovered a different effect of sustained ER stress between neurons and $\beta$ cells. Whereas terminal UPR kills $\beta$ cells in the Manf $^{-1-}$ pancreas, there is no neurodegeneration in the midbrain dopamine system of Manf $f^{f l f l}:: N e s t i n^{C r e /+}$ mice despite the upregulation of UPR genes. However, the lack of MANF decreases survival of cultured cortical neurons when exposed to chemically-induced ER stress. This is the first study analyzing the role of endogenous MANF in the nigrostriatal dopamine system with the conclusion that in our transgenic mouse model, MANF expression 
does not seem to be needed for the proper function of midbrain dopamine neurons in the aging brain.

\section{References}

Airavaara M, Mijatovic J, Vihavainen T, Piepponen TP, Saarma M, Ahtee L (2006) In heterozygous GDNF knockout mice the response of striatal dopaminergic system to acute morphine is altered. Synapse 59:321-329.

Airavaara M, Shen H, Kuo CC, Peränen J, Saarma M, Hoffer B, Wang Y (2009) Mesencephalic astrocyte-derived neurotrophic factor reduces ischemic brain injury and promotes behavioral recovery in rats. J Comp Neurol 515:116-124.

Albert K, Voutilainen MH, Domanskyi A, Piepponen TP, Ahola S, Tuominen RK, Richie C, Harvey BK, Airavaara M (2019) Downregulation of tyrosine hydroxylase phenotype after AAV injection above substantia nigra: Caution in experimental models of Parkinson's disease. J Neurosci Res 97:346-361.

Anthony TG, Wek RC (2012) TXNIP switches tracks toward a terminal UPR. Cell Metab 16:135-137.

Apostolou A, Shen Y, Liang Y, Luo J, Fang S (2008) Armet, a UPRupregulated protein, inhibits cell proliferation and ER stress-induced cell death. Exp Cell Res 314:2454-2467.

Bell PA, Dennis EP, Hartley CL, Jackson RM, Porter A, BootHandford RP, Pirog KA, Briggs MD (2019) Mesencephalic astrocyte-derived neurotropic factor is an important factor in chondrocyte ER homeostasis. Cell Stress Chaperones 24:159-173.

Carpenter AE, Jones TR, Lamprecht MR, Clarke C, Kang IH, Friman $\mathrm{O}$, Guertin DA, Chang JH, Lindquist RA, Moffat J, Golland P, Sabatini DM (2006) CellProfiler: image analysis software for identifying and quantifying cell phenotypes. Genome Biol 7:R100.

Chen YC, Sundvik M, Rozov S, Priyadarshini M, Panula P (2012) MANF regulates dopaminergic neuron development in larval zebrafish. Dev Biol 370:237-249.

Danilova T, Belevich I, Li H, Palm E, Jokitalo E, Otonkoski T, Lindahl $\mathrm{M}$ (2019a) MANF is required for the postnatal expansion and maintenance of pancreatic $\beta$-cell mass in mice. Diabetes 68:66-80.

Danilova T, Galli E, Pakarinen E, Palm E, Lindholm P, Saarma M, Lindahl M (2019b) Mesencephalic astrocyte-derived neurotrophic factor (MANF) is highly expressed in mouse tissues with metabolic function. Front Endocrinol (Lausanne) 10:765.

Darlington PJ, Goldman JS, Cui QL, Antel JP, Kennedy TE (2008) Widespread immunoreactivity for neuronal nuclei in cultured human and rodent astrocytes. J Neurochem 104:1201-1209.

Declercq J, Brouwers B, Pruniau VP, Stijnen P, de Faudeur G, Tuand K, Meulemans S, Serneels L, Schraenen A, Schuit F, Creemers JW (2015) Metabolic and behavioural phenotypes in Nestin-Cre mice are caused by hypothalamic expression of human growth hormone. PLoS One 10:e0135502.

DeKosky ST, Scheff SW (1990) Synapse loss in frontal cortex biopsies in Alzheimer's disease: Correlation with cognitive severity. Ann Neurol 27:457-464.

Domanskyi A, Saarma M, Airavaara M (2015) Prospects of neurotrophic factors for Parkinson's disease: Comparison of protein and gene therapy. Hum Gene Ther 26:550-559.

Dubois NC, Hofmann D, Kaloulis K, Bishop JM, Trumpp A (2006) Nestin-Cre transgenic mouse line Nes-Cre1 mediates highly efficient $\mathrm{Cre} / \mathrm{loxP}$ mediated recombination in the nervous system, kidney, and somite-derived tissues. Genesis 44:355-360.

Gajera CR, Fernandez R, Postupna N, Montine KS, Fox EJ, Tebaykin D, Angelo M, Bendall SC, Keene CD, Montine TJ (2019) Mass synaptometry: High-dimensional multi parametric assay for single synapses. J Neurosci Methods 312:73-83.

Galichet C, Lovell-Badge R, Rizzoti K (2010) Nestin-Cre mice are affected by hypopituitarism, which is not due to significant activity of the transgene in the pituitary gland. PLoS One 5:e11443.

Galli S, Lopes DM, Ammari R, Kopra J, Millar SE, Gibb A, Salinas PC (2014) Deficient Wnt signalling triggers striatal synaptic degeneration and impaired motor behaviour in adult mice. Nat Commun 5:4992.

Giusti SA, Vercelli CA, Vogl AM, Kolarz AW, Pino NS, Deussing JM, Refojo D (2014) Behavioral phenotyping of Nestin-Cre mice: Implications for genetic mouse models of psychiatric disorders. J Psychiatr Res 55:87-95.

Gladwyn-Ng I, Cordón-Barris L, Alfano C, Creppe C, Couderc T, Morelli G, Thelen N, America M, Bessières B, Encha-Razavi F, Bonnière $M$, Suzuki IK, Flamand $M$, Vanderhaeghen $P$, Thiry $M$, Lecuit M, Nguyen L (2018) Stress-induced unfolded protein response contributes to Zika virus-associated microcephaly. Nat Neurosci 21:63-71.

Glembotski CC, Thuerauf DJ, Huang C, Vekich JA, Gottlieb RA, Doroudgar S (2012) Mesencephalic astrocyte-derived neurotrophic factor protects the heart from ischemic damage and is selectively secreted upon sarco/endoplasmic reticulum calcium depletion. J Biol Chem 287:25893-25904.

Godin JD, Creppe C, Laguesse S, Nguyen L (2016) Emerging roles for the unfolded protein response in the developing nervous system. Trends Neurosci 39:394-404.

Hakonen E, Chandra V, Fogarty CL, Yu NY, Ustinov J, Katayama S, Galli E, Danilova T, Lindholm P, Vartiainen A, Einarsdottir E, Krjutškov K, Kere J, Saarma M, Lindahl M, Otonkoski T (2018) MANF protects human pancreatic beta cells against stress-induced cell death. Diabetologia 61:2202-2214.

Hao F, Yang C, Chen SS, Wang YY, Zhou W, Hao Q, Lu T, Hoffer B, Zhao LR, Duan WM, Xu QY (2017) Long-term protective effects of AAV9-mesencephalic astrocyte-derived neurotrophic factor gene transfer in parkinsonian rats. Exp Neurol 291:120-133.

Hartman JH, Richie CT, Gordon KL, Mello DF, Castillo P, Zhu A, Wang Y, Hoffer BJ, Sherwood DR, Meyer JN, Harvey BK (2019) MANF deletion abrogates early larval Caenorhabditis elegans stress response to tunicamycin and Pseudomonas aeruginosa. Eur J Cell Biol 98.

Hellman M, Arumäe U, Yu LY, Lindholm P, Peränen J, Saarma M, Permi P (2011) Mesencephalic astrocyte-derived neurotrophic factor (MANF) has a unique mechanism to rescue apoptotic neurons. J Biol Chem 286:2675-2680.

Hetz C, Saxena S (2017) ER stress and the unfolded protein response in neurodegeneration. Nat Rev Neurol 13:477-491.

Hoozemans JJ, van Haastert ES, Eikelenboom P, de Vos RA, Rozemuller JM, Scheper W (2007) Activation of the unfolded protein response in Parkinson's disease. Biochem Biophys Res Commun 354:707-711.

Hunn BH, Cragg SJ, Bolam JP, Spillantini MG, Wade-Martins R (2015) Impaired intracellular trafficking defines early Parkinson's disease. Trends Neurosci 38:178-188.

Jones TR, Carpenter AE, Lamprecht MR, Moffat J, Silver SJ, Grenier JK, Castoreno AB, Eggert US, Root DE, Golland P, Sabatini DM (2009) Scoring diverse cellular morphologies in image-based screens with iterative feedback and machine learning. Proc Natl Acad Sci USA 106:1826-1831.

Kaneko M, Niinuma Y, Nomura Y (2003) Activation signal of nuclear factor-kappa $B$ in response to endoplasmic reticulum stress is transduced via IRE1 and tumor necrosis factor receptor-associated factor 2. Biol Pharm Bull 26:931-935.

Laguesse S, Creppe C, Nedialkova DD, Prévot PP, Borgs L, Huysseune S, Franco B, Duysens G, Krusy N, Lee G, Thelen N, Thiry M, Close P, Chariot A, Malgrange B, Leidel SA, Godin JD, Nguyen $L$ (2015) A dynamic unfolded protein response contributes to the control of cortical neurogenesis. Dev Cell 35:553-567.

Lee AS (2005) The ER chaperone and signaling regulator GRP78/BiP as a monitor of endoplasmic reticulum stress. Methods 35:373381.

Lerner AG, Upton JP, Praveen PV, Ghosh R, Nakagawa Y, Igbaria A, Shen S, Nguyen V, Backes BJ, Heiman M, Heintz N, Greengard P, Hui S, Tang Q, Trusina A, Oakes SA, Papa FR (2012) IRE1 $\alpha$ induces thioredoxin-interacting protein to activate the NLRP3 inflammasome and promote programmed cell death under irremediable ER stress. Cell Metab 16:250-264. 
Li L, Hu GK (2015) Pink1 protects cortical neurons from thapsigargininduced oxidative stress and neuronal apoptosis. Biosci. Rep 35.

Lin JH, Li H, Zhang Y, Ron D, Walter P (2009) Divergent effects of PERK and IRE1 signaling on cell viability. PLoS One 4:e4170.

Lindahl M, Danilova T, Palm E, Lindholm P, Võikar V, Hakonen E, Ustinov J, Andressoo JO, Harvey BK, Otonkoski T, Rossi J, Saarma M (2014) MANF is indispensable for the proliferation and survival of pancreatic $\beta$ cells. Cell Rep 7:366-375.

Lindahl M, Chalazonitis A, Palm E, Pakarinen E, Danilova T, Pham TD, Setlik W, Rao M, Võikar V, Huotari J, Kopra J, Andressoo JO, Piepponen PT, Airavaara M, Panhelainen A, Gershon MD, Saarma M (2020) Cerebral dopamine neurotrophic factor-deficiency leads to degeneration of enteric neurons and altered brain dopamine neuronal function in mice. Neurobiol Dis 134:104696.

Lindholm P, Voutilainen MH, Laurén J, Peränen J, Leppänen VM, Andressoo JO, Lindahl M, Janhunen S, Kalkkinen N, Timmusk T, Tuominen RK, Saarma M (2007) Novel neurotrophic factor CDNF protects and rescues midbrain dopamine neurons in vivo. Nature 448:73-77.

Lindholm P, Peränen J, Andressoo JO, Kalkkinen N, Kokaia Z, Lindvall O, Timmusk T, Saarma M (2008) MANF is widely expressed in mammalian tissues and differently regulated after ischemic and epileptic insults in rodent brain. Mol Cell Neurosci 39:356-371.

Lindholm D, Korhonen L, Eriksson O, Kõks S (2017) Recent insights into the role of unfolded protein response in ER stress in health and disease. Front Cell Dev Biol 5:48.

Lindström R, Lindholm P, Kallijärvi J, Palgi M, Saarma M, Heino TI (2016) Exploring the conserved role of MANF in the unfolded protein response in Drosophila melanogaster. PLoS One 11: e0151550.

Liu Y, Zhang J, Jiang M, Cai Q, Fang J, Jin L (2018) MANF improves the MPP $(+) /$ MPTP-induced Parkinson's disease via improvement of mitochondrial function and inhibition of oxidative stress. Am J Transl Res 10:1284-1294.

Martínez G, Vidal RL, Mardones P, Serrano FG, Ardiles AO, Wirth C, Valdés $P$, Thielen P, Schneider BL, Kerr B, Valdés JL, Palacios AG, Inestrosa NC, Glimcher LH, Hetz C (2016) Regulation of memory formation by the transcription factor XBP1. Cell Rep 14:1382-1394.

Mätlik K, Yu LY, Eesmaa A, Hellman M, Lindholm P, Peränen J, Galli E, Anttila J, Saarma M, Permi P, Airavaara M, Arumäe U (2015) Role of two sequence motifs of mesencephalic astrocyte-derived neurotrophic factor in its survival-promoting activity. Cell Death Dis 6:e2032.

Mätlik K, Anttila JE, Kuan-Yin T, Smolander O-P, Pakarinen E, Lehtonen L, Abo-Ramadan U, Lindholm P, Zheng C, Harvey B, Arumäe U, Lindahl M, Airavaara M (2018) Poststroke delivery of MANF promotes functional recovery in rats. Am J Transl Res 4: eaap8957.

Morita S, Villalta SA, Feldman HC, Register AC, Rosenthal W, Hoffmann-Petersen IT, Mehdizadeh M, Ghosh R, Wang L, ColonNegron K, Meza-Acevedo R, Backes BJ, Maly DJ, Bluestone JA, Papa FR (2017) Targeting ABL-IRE1 $\alpha$ signaling spares ERstressed pancreatic $\beta$ cells to reverse autoimmune diabetes. Cell Metab 25:1207.

Neves J, Zhu J, Sousa-Victor P, Konjikusic M, Riley R, Chew S, Qi Y, Jasper H, Lamba DA (2016) Immune modulation by MANF promotes tissue repair and regenerative success in the retina. Science 353:aaf3646.

$\mathrm{Ni} \mathrm{H}$, Rui Q, Li D, Gao R, Chen G (2018) The role of IRE1 signaling in the central nervous system diseases. Curr Neuropharmacol 16:1340-1347.

Oh-Hashi K, Hirata Y, Kiuchi K (2013) Transcriptional regulation of mouse mesencephalic astrocyte-derived neurotrophic factor in Neuro2a cells. Cell Mol Biol Lett 18:398-415.

Ohno M (2018) PERK as a hub of multiple pathogenic pathways leading to memory deficits and neurodegeneration in Alzheimer's disease. Brain Res Bull 141:72-78.
Overk CR, Masliah E (2014) Pathogenesis of synaptic degeneration in Alzheimer's disease and Lewy body disease. Biochem Pharmacol 88:508-516.

Palgi M, Lindström R, Peränen J, Piepponen TP, Saarma M, Heino TI (2009) Evidence that DmMANF is an invertebrate neurotrophic factor supporting dopaminergic neurons. Proc Natl Acad Sci USA 106:2429-2434.

Parkash V, Lindholm P, Peränen J, Kalkkinen N, Oksanen E, Saarma M, Leppänen VM, Goldman A (2009) The structure of the conserved neurotrophic factors MANF and CDNF explains why they are bifunctional. Protein Eng Des Sel 22:233-241.

Penttinen AM, Suleymanova I, Albert K, Anttila J, Voutilainen $\mathrm{MH}$, Airavaara M (2016) Characterization of a new low-dose 6-hydroxydopamine model of Parkinson's disease in rat. J Neurosci Res 94:318-328.

Petrova P, Raibekas A, Pevsner J, Vigo N, Anafi M, Moore MK, Peaire AE, Shridhar V, Smith DI, Kelly J, Durocher Y, Commissiong JW (2003) MANF: A new mesencephalic, astrocyte-derived neurotrophic factor with selectivity for dopaminergic neurons. J Mol Neurosci 20:173-188.

Richman C, Rashid S, Prashar S, Mishra R, Selvaganapathy PR, Gupta BP (2018) C. elegans MANF homolog is necessary for the protection of dopaminergic neurons and ER unfolded protein response. Front Neurosci 12:544.

Rueden CT, Schindelin J, Hiner MC, DeZonia BE, Walter AE, Arena $E T$, Eliceiri KW (2017) ImageJ2: ImageJ for the next generation of scientific image data. BMC Bioinformatics 18:529.

Ruland J, Duncan GS, Elia A, del Barco Barrantes I, Nguyen L, Plyte S, Millar DG, Bouchard D, Wakeham A, Ohashi PS, Mak TW (2001) $\mathrm{BcIX}$ is a positive regulator of antigen receptor-induced activation of NF-kappaB and neural tube closure. Cell 104:33-42.

Sado M, Yamasaki Y, Iwanaga T, Onaka Y, Ibuki T, Nishihara S, Mizuguchi H, Momota H, Kishibuchi R, Hashimoto T, Wada D, Kitagawa H, Watanabe TK (2009) Protective effect against Parkinson's disease-related insults through the activation of XBP1. Brain Res 1257:16-24.

Shen $Y$, Sun A, Wang $Y$, Cha D, Wang $H$, Wang F, Feng L, Fang S, Shen $Y$ (2012) Upregulation of mesencephalic astrocyte-derived neurotrophic factor in glial cells is associated with ischemia-induced glial activation. J Neuroinflammation 9:254.

Sims-Robinson C, Bakeman A, Glasser R, Boggs J, Pacut C, Feldman EL (2016) The role of endoplasmic reticulum stress in hippocampal insulin resistance. Expr Patterns 277:261-267.

Stratoulias V, Heino TI (2015) Analysis of the conserved neurotrophic factor MANF in the Drosophila adult brain. Gene Expr Patterns 18:8-15.

Tam AB, Mercado EL, Hoffmann A, Niwa M (2012) ER stress activates NF- $\kappa$ B by integrating functions of basal IKK activity, IRE1 and PERK. PLoS One 7:e45078.

Tronche F, Kellendonk C, Kretz O, Gass P, Anlag K, Orban PC, Bock R, Klein R, Schütz G (1999) Disruption of the glucocorticoid receptor gene in the nervous system results in reduced anxiety. Nat Genet 23:99-103.

Tseng KY, Danilova T, Domanskyi A, Saarma M, Lindahl M, Airavaara M (2017) MANF is essential for neurite extension and neuronal migration in the developing cortex. eNeuro 4:ENEURO. 0214-17.2017.

Unal-Cevik I, Kilinç M, Gürsoy-Ozdemir Y, Gurer G, Dalkara T (2004) Loss of NeuN immunoreactivity after cerebral ischemia does not indicate neuronal cell loss: A cautionary note. Brain Res 1015:169-174.

Valdés P, Mercado G, Vidal RL, Molina C, Parsons G, Court FA, Martinez A, Galleguillos D, Armentano D, Schneider BL, Hetz C (2014) Control of dopaminergic neuron survival by the unfolded protein response transcription factor XBP1. Proc Natl Acad Sci USA 111:6804-6809.

Walter P, Ron D (2011) The unfolded protein response: From stress pathway to homeostatic regulation. Science 334:1081-1086.

Wang D, Hou C, Cao Y, Cheng Q, Zhang L, Li H, Feng L, Shen Y (2018) XBP1 activation enhances MANF expression via binding to endoplasmic reticulum stress response elements within 
MANF promoter region in hepatitis B. Int $\mathrm{J}$ Biochem Cell Biol 99:140-146.

Voutilainen MH, Back S, Porsti E, Toppinen L, Lindgren L, Lindholm P, Peranen J, Saarma M, Tuominen RK (2009) Mesencephalic astrocyte-derived neurotrophic factor is neurorestorative in rat model of Parkinson's disease. J. Neurosci 29:9651-9659.

Yan Y, Rato C, Rohland L, Preissler S, Ron D (2019) MANF antagonizes nucleotide exchange by the endoplasmic reticulum chaperone BiP. Nat Commun 10:541.

Yang S, Huang S, Gaertig MA, Li XJ, Li S (2014) Age-dependent decrease in chaperone activity impairs MANF expression, leading to Purkinje cell degeneration in inducible SCA17 mice. Neuron 81:349-365.

Yang S, Yang $\mathrm{H}$, Chang R, Yin P, Yang Y, Yang W, Huang S, Gaertig MA, Li S, Li XJ (2017) MANF regulates hypothalamic control of food intake and body weight. Nat Commun 8:579.
Yates JW, Meij JT, Sullivan JR, Richtand NM, Yu L (2007) Bimodal effect of amphetamine on motor behaviors in C57BL/6 mice. Neurosci Lett 427:66-70.

Yavarna T, Al-Dewik N, Al-Mureikhi M, Ali R, Al-Mesaifri F, Mahmoud L, Shahbeck N, Lakhani S, AlMulla M, Nawaz Z, Vitazka P, Alkuraya FS, Ben-Omran T (2015) High diagnostic yield of clinical exome sequencing in Middle Eastern patients with Mendelian disorders. Hum Genet 134:967-980.

Zhang Y, Liu W, Zhou Y, Ma C, Li S, Cong B (2014) Endoplasmic reticulum stress is involved in restraint stress-induced hippocampal apoptosis and cognitive impairments in rats. Physiol Behav 131:41-48.

Zhao YY, Yan Z, Zhao S, Li J Yin (2015) The dynamic changes of endoplasmic reticulum stress pathway markers GRP78 and CHOP in the hippocampus of diabetic mice. Brain Res Bull 111:27-35. 